\title{
Report on INL Activities for Uncertainty Reduction Analysis of FY10
}

G. Palmiotti

H. Hiruta

M. Salvatores

D. Fynan

September 2010

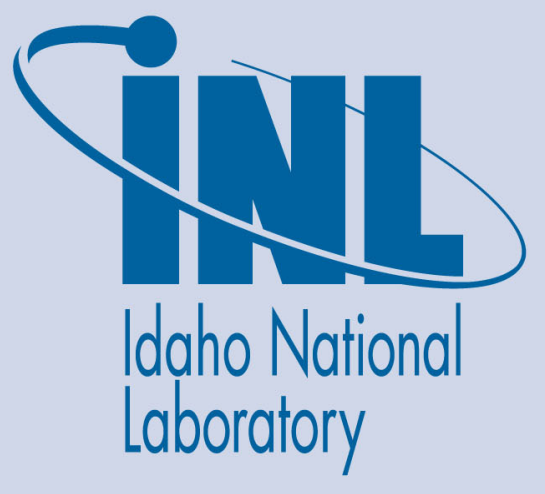

The INL is a U.S. Department of Energy National Laboratory operated by Battelle Energy Alliance 
INL/EXT-10-19969

FCRD-TRAN-2010-000152

\title{
Report on INL Activities for Uncertainty Reduction Analysis of FY10
}

\author{
G. Palmiotti \\ H. Hiruta \\ M. Salvatores \\ D. Fynan
}

September 2010

Idaho National Laboratory

Fuel Cycle Research \& Development

Idaho Falls, Idaho 83415

http://www.inl.gov

Prepared for the

U.S. Department of Energy

Through the INL LDRD Program

Under DOE Idaho Operations Office

Contract DE-AC07-05ID14517 


\section{DISCLAIMER}

This information was prepared as an account of work sponsored by an agency of the U.S. Government. Neither the U.S. Government nor any agency thereof, nor any of their employees, makes any warranty, expressed or implied, or assumes any legal liability or responsibility for the accuracy, completeness, or usefulness, of any information, apparatus, product, or process disclosed, or represents that its use would not infringe privately owned rights. References herein to any specific commercial product, process, or service by trade name, trade mark, manufacturer, or otherwise, does not necessarily constitute or imply its endorsement, recommendation, or favoring by the U.S. Government or any agency thereof. The views and opinions of authors expressed herein do not necessarily state or reflect those of the U.S. Government or any agency thereof. 
Report on INL Activities for Uncertainty Reduction Analysis of FY10

September 2010 


\section{SUMMARY}

The work scope of this project related to the Work Packages of "Uncertainty Reduction Analyses" with the goal of reducing nuclear data uncertainties is to produce a set of improved nuclear data to be used both for a wide range of validated advanced fast reactor design calculations, and for providing guidelines for further improvements of the ENDF/B files (i.e. ENDF/B-VII, and future releases).

This report presents the status of activities performed at INL under the FC R\&D Work Package previously mentioned. First an analysis of uncertainty evaluation is presented using the new covariance data (AFCI version 1.2) made available by BNL. Then, analyses of a number of experiments, among those selected in the previous fiscal year and available, are presented making use of ENDF/B-VII data. These experiments include: updating of the ZPR-6/7 assembly (improved model and spectral indices), ZPPR-9 assembly (only simplified model available), ZPPR-10 (full detailed model), and irradiation experiments. These last experiments include PROFIL-1 were a new methodology has been employed in the Monte Carlo calculations, and also a deterministic analysis has been performed. This is the first time the Monte Carlo approach and ENDF/B-VII have been used for the PROFIL experiments. The PROFIL-2 and TRAPU experiments have been for the moment only modeled and a full analysis of the irradiation results will be finalized next fiscal year. 
Report on INL Activities for Uncertainty Reduction Analysis of FY10

September 2010 


\section{CONTENTS}

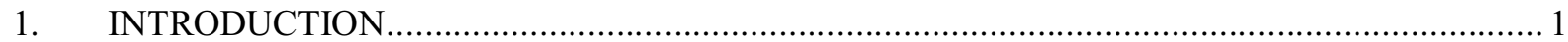

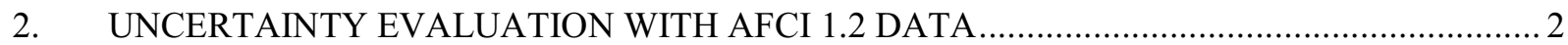

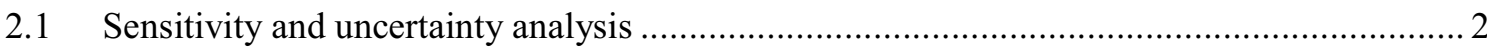

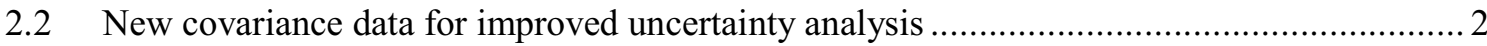

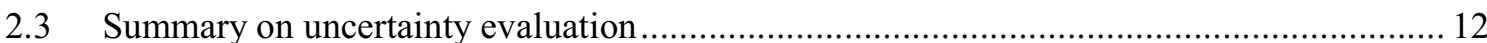

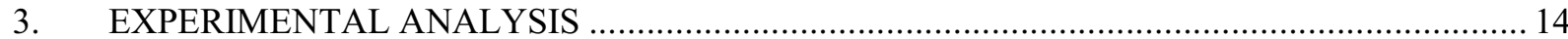

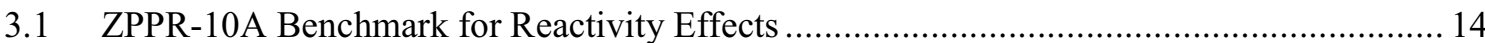

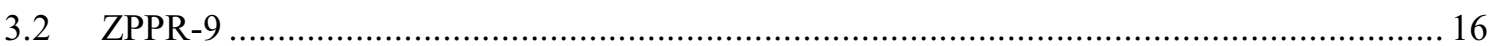

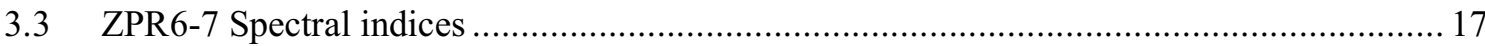

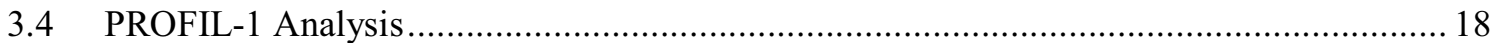

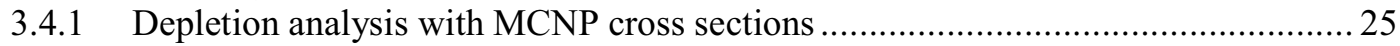

3.4.2 Depletion analysis with deterministic methodology ….......................................... 30

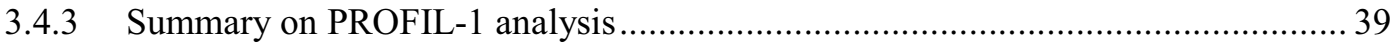

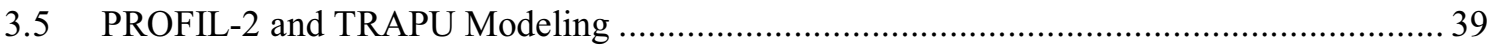

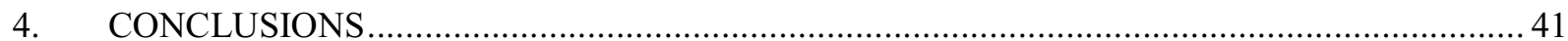

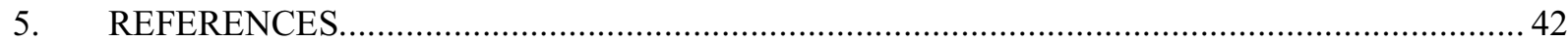


Report on INL Activities for Uncertainty Reduction Analysis of FY10

September 2010 
Title

Date 


\section{TRANSMUTATION TECHNOLOGY/NUCLEAR DATA}

\section{INTRODUCTION}

Recent extensive sensitivity/uncertainty studies, performed partly in the frame of AFCI (now FCR\&D) and extensively supported within an international OECD-NEA initiative, have quantified for the first time the impact of current nuclear data uncertainties on design parameters of the major FCR\&D and GEN-IV systems, and in particular on Na-cooled fast reactors with different fuels (oxide or metal), fuel composition (e.g. different $\mathrm{Pu} / \mathrm{TRU}$ ratios) and different conversion ratios.

These studies have pointed out that present uncertainties on the nuclear data should be significantly reduced, in order to get full benefit from the advanced modeling and simulation initiatives.

Only a parallel effort in advanced simulation and in nuclear data improvement will enable to provide designers with more general and well validated calculation tools that would be able to meet design target accuracies.

The work scope of this project related to the Work Packages of "Uncertainty Reduction Analyses" with the goal of reducing nuclear data uncertainties is to produce a set of improved nuclear data to be used both for a wide range of validated advanced fast reactor design calculations, and for providing guidelines for further improvements of the ENDF/B files (i.e. ENDF/B-VII, and future releases).

This report presents the status of activities performed at INL under the FCR\&D Work Package previously mentioned. First an analysis of uncertainty evaluation is presented using the new covariance data (AFCI version 1.2) made available by BNL. Then, analyses of a number of experiments, among those selected in the previous fiscal year and available, are presented making use of ENDF/B-VII data. These experiments include: updating of the ZPR-6/7 assembly (improved model and spectral indices), ZPPR-9 assembly (only simplified model available), ZPPR-10 (full detailed model), and irradiation experiments. These last experiments include PROFIL-1 were a new methodology has been employed in the Monte Carlo calculations, and also a deterministic analysis has been performed. The PROFIL-2 and TRAPU experiments have been for the moment only modeled and a full analysis of the irradiation results will be finalized next fiscal year. 


\section{UNCERTAINTY EVALUATION WITH AFCI 1.2 DATA}

The first and most significant recent initiative aiming to a systematic nuclear data uncertainty impact assessment, was taken by the Working Party on Evaluation Cooperation (WPEC) of the OECD Nuclear Energy Agency Nuclear Science Committee when it established a Subgroup (called 26) to develop a systematic approach to define data needs for advanced reactor systems and to make a comprehensive study of such needs for Generation-IV (Gen-IV) reactors. The subgroup was established at the end of 2005, and a final report has been published in 2008 [1]. A comprehensive sensitivity and uncertainty study was performed to evaluate the impact of neutron cross-section uncertainty on the most significant integral parameters related to the core and fuel cycle of a wide range of innovative systems, even beyond the Gen-IV range of systems. In particular, results have been obtained for the Advanced Breeder Reactor (ABR), the Sodium-cooled Fast Reactor (SFR), the European Fast Reactor (EFR), the Gas-cooled Fast Reactor (GFR), the Lead-cooled Fast Reactor (LFR), and the Accelerator Driven Minor Actinide Burner (ADMAB). These systems correspond to current studies within the Generation-IV initiative, the Advanced Fuel Cycle Initiative (AFCI), and the advanced fuel cycle and Partitioning/Transmutation studies in Japan and Europe.

\subsection{Sensitivity and uncertainty analysis}

In order to perform the analysis, state-of-the-art sensitivity and uncertainty methods have been used based on the ERANOS code system [2].

The integral parameter uncertainties were initially calculated using covariance data developed in a joint effort of several laboratories contributing to the Subgroup activity. This set of covariance matrices was referred to as BOLNA [3].

The calculated integral parameter uncertainties, resulting from the initially assessed uncertainties on nuclear data of the BOLNA set, were found rather acceptable for the early phases of design feasibility studies. In fact, the uncertainty on keff was found to be less than $2 \%$ for all systems (with the exception of the Accelerator Driven System, ADS) and reactivity coefficient uncertainties below 20\%. Power distributions uncertainties are also relatively small, except, once more, in the case of the ADS.

However, later conceptual and design optimization phases of selected reactor and fuel cycle concepts will need improved data and methods, in order to reduce margins, both for economical and safety reasons. For this purpose, a compilation of preliminary "Design Target Accuracies" has been put together and a target accuracy assessment has been performed to provide an indicative quantitative evaluation of nuclear data improvement requirements by isotope, nuclear reaction and energy range, in order to meet the Design target accuracies, as compiled in the present study. First priorities were formulated on the basis of common needs for fast reactors and, separately, thermal systems. These priority items (see Table I) have been included in the High Priority Request List (HPRL) of the OECD-NEA DataBank.

\subsection{New covariance data for improved uncertainty analysis}

Very recently, an effort lead by BNL [4] has produced an improved version of the initial covariance data (here called AFCI 1.2) with an energy group structure of 33 groups (instead of 15), and revised uncertainties have been calculated on the wide range of Fast Reactor systems considered above. The 15 group energy structure was intended to cover the entire energy spectrum so that a VHTR reactor and a high burn up PWR could be included in the Subgroup 26 study. The 33 group energy structure is devoted to specifically cover the fast reactor energy range. Typical results obtained with AFCI 1.2 and comparisons with previous data obtained with the BOLNA data are given in Tables II-XIII.

The overall uncertainties obtained with AFCI 1.2 confirm the order of magnitude of integral parameters uncertainties originally observed with BOLNA. The role of the uncertainty on U-238 inelastic cross 
section is confirmed, as is the role of the Pu-241 fission cross section uncertainty, despite some significant variation between the uncertainties values in AFCI 1.2 with respect to BOLNA (see figure 1). In fact the $\mathrm{Pu}-241$ fission uncertainty stays approximately the same between $\sim 1 \mathrm{MeV}$ and $\sim 1 \mathrm{keV}$ and differs between the two covariance data libraries very strongly only above and below those energy values.

Table I. Summary of Highest Priority Target Accuracies for Fast Reactors from Subgroup 26

\begin{tabular}{|c|c|c|c|c|}
\hline & \multirow{3}{*}{$\begin{array}{c}\text { Energy Range } \\
6.07 \div 0.498 \mathrm{MeV}\end{array}$} & \multirow{3}{*}{$\begin{array}{c}\begin{array}{c}\text { Current } \\
\text { (BOLNA) }\end{array} \\
\text { Accuracy (\%) } \\
10 \div 20\end{array}$} & \multirow{3}{*}{$\begin{array}{c}\begin{array}{c}\text { Target } \\
\text { Accuracy (\%) }\end{array} \\
2 \div 3\end{array}$} \\
\hline & & & & \\
\hline \multirow{2}{*}{$\mathrm{U} 238$} & $\sigma_{\text {inel }}$ & & & \\
\hline & $\sigma_{\text {capt }}$ & $24.8 \div 2.04 \mathrm{keV}$ & $3 \div 9$ & $1.5 \div 2$ \\
\hline $\mathrm{Pu} 241$ & $\sigma_{\text {fiss }}$ & $1.35 \mathrm{MeV} \div 454 \mathrm{eV}$ & $8 \div 20$ & $\begin{array}{c}2 \div 3 \\
(\mathrm{SFR}, \mathrm{GFR}, \mathrm{LFR}) \\
5 \div 8 \\
(\mathrm{ABTR}, \mathrm{EFR})\end{array}$ \\
\hline $\mathrm{Pu} 239$ & $\sigma_{\text {capt }}$ & $498 \div 2.04 \mathrm{keV}$ & $7 \div 15$ & $4 \div 7$ \\
\hline \multirow{2}{*}{$\mathrm{Pu} 240$} & $\sigma_{\text {fiss }}$ & $1.35 \div 0.498 \mathrm{MeV}$ & 6 & $1.5 \div 2$ \\
\hline & $v$ & $1.35 \div 0.498 \mathrm{MeV}$ & 4 & $1 \div 3$ \\
\hline $\mathrm{Pu} 242$ & $\sigma_{\text {fiss }}$ & $2.23 \div 0.498 \mathrm{MeV}$ & $19 \div 21$ & $3 \div 5$ \\
\hline $\mathrm{Pu} 238$ & $\sigma_{\text {fiss }}$ & $1.35 \div 0.183 \mathrm{MeV}$ & 17 & $3 \div 5$ \\
\hline $\mathrm{Am} 242 \mathrm{~m}$ & $\sigma_{\text {fiss }}$ & $1.35 \mathrm{MeV} \div 67.4 \mathrm{keV}$ & 17 & $3 \div 4$ \\
\hline Am241 & $\sigma_{\text {fiss }}$ & $6.07 \div 2.23 \mathrm{MeV}$ & 12 & 3 \\
\hline $\mathrm{Cm} 244$ & $\sigma_{\text {fiss }}$ & $1.35 \div 0.498 \mathrm{MeV}$ & 50 & 5 \\
\hline $\mathrm{Cm} 245$ & $\sigma_{\text {fiss }}$ & $183 \div 67.4 \mathrm{keV}$ & 47 & 7 \\
\hline Fe56 & $\sigma_{\text {inel }}$ & $2.23 \div 0.498 \mathrm{MeV}$ & $16 \div 25$ & $3 \div 6$ \\
\hline $\mathrm{Na} 23$ & $\sigma_{\text {inel }}$ & $1.35 \div 0.498 \mathrm{MeV}$ & 28 & $4 \div 10$ \\
\hline $\mathrm{Pb} 206$ & $\sigma_{\text {inel }}$ & $2.23 \div 1.35 \mathrm{MeV}$ & 14 & 3 \\
\hline $\mathrm{Pb} 207$ & $\sigma_{\text {inel }}$ & $1.35 \div 0.498 \mathrm{MeV}$ & 11 & 3 \\
\hline \multirow{2}{*}{ Si28 } & $\sigma_{\text {inel }}$ & $6.07 \div 1.35 \mathrm{MeV}$ & $14 \div 50$ & $3 \div 6$ \\
\hline & $\sigma_{\text {capt }}$ & $19.6 \div 6.07 \mathrm{MeV}$ & 53 & 6 \\
\hline
\end{tabular}


Table II. ADMAB-EOC: keff Uncertainty (\%) using AFCI 1.2

\begin{tabular}{|c|c|c|c|c|c|c|}
\hline ISOTOPE & CAPTURE & ELASTIC & NU & INELASTIC & FISSION & SUM \\
\hline PU238 & 0.04 & 0.00 & 0.14 & 0.03 & 1.29 & 1.29 \\
\hline CM245 & 0.01 & 0.00 & 0.12 & 0.01 & 1.12 & 1.13 \\
\hline CM244 & 0.64 & 0.00 & 0.56 & 0.07 & 0.72 & 1.12 \\
\hline AM241 & 0.60 & 0.00 & 0.30 & 0.19 & 0.83 & 1.08 \\
\hline PU241 & 0.08 & 0.00 & 0.03 & 0.01 & 0.95 & 0.95 \\
\hline CM242 & 0.05 & 0.00 & 0.08 & $\mathbf{0 . 0 3}$ & 0.68 & 0.68 \\
\hline AM243 & 0.30 & 0.00 & 0.09 & 0.24 & 0.40 & 0.56 \\
\hline NP237 & 0.18 & 0.00 & 0.06 & 0.18 & 0.35 & 0.44 \\
\hline BI209 & 0.06 & 0.05 & 0.00 & 0.30 & 0.00 & 0.31 \\
\hline PU240 & 0.13 & 0.00 & 0.16 & 0.02 & 0.15 & 0.26 \\
\hline AM242M & 0.02 & 0.00 & 0.02 & 0.01 & 0.24 & 0.24 \\
\hline N15 & 0.01 & 0.22 & $\mathbf{0 . 0 0}$ & 0.01 & 0.00 & 0.22 \\
\hline PU242 & 0.07 & 0.00 & 0.04 & 0.03 & 0.19 & 0.21 \\
\hline PB206 & 0.02 & 0.01 & 0.00 & 0.19 & 0.00 & 0.19 \\
\hline PU239 & 0.08 & 0.01 & 0.07 & 0.08 & 0.11 & 0.18 \\
\hline SUM & 0.98 & 0.24 & 0.70 & 0.55 & 2.42 & 2.77 \\
\hline
\end{tabular}

Table III. ADMAB-EOC: keff Uncertainty Difference (\%) between AFCI1.2 and BOLNA (major contributions)

\begin{tabular}{|c|c|c|c|c|c|c|}
\hline ISOTOPE & CAPTURE & ELASTIC & NU & INELASTIC & FISSION & SUM \\
\hline CM244 & 0.45 & 0.00 & 0.17 & 0.02 & -1.38 & -1.03 \\
\hline PU238 & 0.00 & 0.00 & -0.18 & 0.02 & 0.79 & 0.70 \\
\hline FE56 & 0.05 & -0.01 & 0.00 & -0.69 & 0.00 & -0.63 \\
\hline CM242 & 0.04 & 0.00 & 0.03 & 0.02 & 0.44 & 0.44 \\
\hline BI209 & 0.06 & 0.05 & 0.00 & 0.30 & 0.00 & 0.31 \\
\hline AM241 & 0.22 & 0.00 & 0.15 & -0.05 & 0.11 & 0.22 \\
\hline N15 & 0.01 & 0.22 & 0.00 & 0.01 & 0.00 & 0.22 \\
\hline SUM & 0.45 & 0.19 & 0.12 & -0.39 & -0.33 & -0.24 \\
\hline
\end{tabular}


Report on INL Activities for Uncertainty Reduction Analysis of FY10

September 2010

Table IV. ABR-Metal-EOC: keff Uncertainty (\%) using AFCI 1.2

\begin{tabular}{|c|c|c|c|c|c|c|}
\hline ISOTOPE & CAPTURE & ELASTIC & NU & INELASTIC & FISSION & SUM \\
\hline U238 & 0.18 & 0.17 & 0.14 & 0.97 & 0.04 & 1.01 \\
\hline PU241 & 0.07 & 0.00 & 0.02 & 0.00 & 0.66 & 0.67 \\
\hline PU238 & 0.02 & 0.00 & 0.06 & 0.01 & 0.56 & 0.56 \\
\hline PU240 & 0.29 & 0.01 & 0.30 & 0.02 & 0.27 & 0.50 \\
\hline PU239 & 0.16 & 0.03 & 0.12 & 0.08 & 0.20 & 0.30 \\
\hline PU242 & 0.09 & 0.00 & 0.04 & 0.02 & 0.19 & 0.21 \\
\hline CM245 & 0.00 & 0.00 & 0.02 & 0.00 & 0.21 & 0.21 \\
\hline FE56 & 0.15 & 0.12 & 0.00 & 0.03 & 0.00 & 0.20 \\
\hline NA23 & 0.00 & 0.07 & 0.00 & 0.08 & 0.00 & 0.11 \\
\hline CM244 & 0.07 & 0.00 & 0.05 & 0.00 & 0.06 & 0.11 \\
\hline AM241 & 0.05 & 0.00 & 0.02 & 0.01 & 0.04 & 0.07 \\
\hline CM242 & 0.01 & 0.00 & 0.01 & 0.00 & 0.06 & 0.06 \\
\hline FE54 & 0.05 & 0.03 & 0.00 & 0.01 & 0.00 & 0.06 \\
\hline AM242M & 0.00 & 0.00 & 0.00 & 0.00 & 0.04 & 0.04 \\
\hline AM243 & 0.03 & 0.00 & 0.01 & 0.01 & 0.03 & 0.04 \\
\hline SUM & 0.44 & 0.23 & 0.37 & 0.98 & 0.98 & 1.52 \\
\hline
\end{tabular}

Table V. ABR-Metal-EOC: keff Uncertainty Difference (\%) between AFCI1.2 and BOLNA (major contributions)

\begin{tabular}{|c|c|c|c|c|c|c|}
\hline ISOTOPE & CAPTURE & ELASTIC & NU & INELASTIC & FISSION & SUM \\
\hline PU238 & 0.00 & 0.00 & -0.08 & 0.01 & 0.34 & 0.31 \\
\hline FE56 & 0.07 & 0.07 & 0.00 & -0.28 & 0.00 & -0.13 \\
\hline NA23 & -0.02 & 0.03 & 0.00 & -0.11 & 0.00 & -0.09 \\
\hline SUM & 0.03 & 0.03 & -0.01 & -0.03 & 0.16 & 0.09 \\
\hline
\end{tabular}

Table VI. SFR: keff Uncertainty (\%)

\begin{tabular}{|c|c|c|c|c|c|c|}
\hline ISOTOPE & CAPTURE & ELASTIC & NU & INELASTIC & FISSION & TOTAL \\
\hline PU238 & 0.06 & 0.00 & 0.16 & 0.02 & 1.31 & 1.32 \\
\hline PU241 & 0.13 & 0.00 & 0.03 & 0.01 & 0.99 & 1.00 \\
\hline PU240 & 0.47 & 0.01 & 0.44 & 0.03 & 0.39 & 0.76 \\
\hline AM242M & 0.09 & 0.00 & 0.05 & 0.02 & 0.65 & 0.66 \\
\hline PU242 & 0.20 & 0.00 & 0.08 & 0.03 & 0.38 & 0.44 \\
\hline CM245 & 0.01 & 0.00 & 0.05 & 0.00 & 0.42 & 0.42 \\
\hline FE56 & 0.20 & 0.20 & 0.00 & 0.04 & 0.00 & 0.29 \\
\hline CM244 & 0.18 & 0.00 & 0.11 & 0.01 & 0.14 & 0.25 \\
\hline U238 & 0.05 & 0.04 & 0.03 & 0.23 & 0.01 & 0.24 \\
\hline PU239 & 0.13 & 0.02 & 0.08 & 0.06 & 0.13 & 0.21 \\
\hline AM241 & 0.10 & 0.00 & 0.04 & 0.01 & 0.09 & 0.14 \\
\hline NA23 & 0.01 & 0.02 & 0.00 & 0.11 & 0.00 & 0.11 \\
\hline CM242 & 0.01 & 0.00 & 0.01 & 0.00 & 0.11 & 0.11 \\
\hline AM243 & 0.06 & 0.00 & 0.01 & 0.02 & 0.06 & 0.09 \\
\hline FE54 & 0.07 & 0.05 & 0.00 & 0.01 & 0.00 & 0.08 \\
\hline TOTAL & 0.64 & 0.21 & 0.51 & 0.27 & 1.91 & 2.11 \\
\hline
\end{tabular}


Table VII. SFR: keff Uncertainty Difference (\%) between AFCI1.2 and BOLNA (major contributions)

\begin{tabular}{|c|c|c|c|c|c|c|}
\hline ISOTOPE & CAPTURE & ELASTIC & NU & INELASTIC & FISSION & TOTAL \\
\hline PU238 & 0.00 & 0.00 & -0.20 & 0.01 & 0.77 & 0.67 \\
\hline FE56 & 0.09 & 0.10 & 0.00 & -0.41 & 0.00 & -0.19 \\
\hline NA23 & -0.01 & 0.01 & 0.00 & -0.15 & 0.00 & -0.15 \\
\hline CM244 & 0.12 & 0.00 & 0.03 & 0.00 & -0.24 & -0.15 \\
\hline B10 & -0.14 & -0.01 & 0.00 & 0.00 & 0.00 & -0.14 \\
\hline PU240 & 0.16 & 0.00 & 0.01 & 0.02 & 0.03 & 0.11 \\
\hline TOTAL & 0.18 & 0.10 & -0.08 & -0.29 & 0.37 & 0.30 \\
\hline
\end{tabular}

Table VIII. EFR: keff Uncertainty (\%)

\begin{tabular}{|c|c|c|c|c|c|c|}
\hline ISOTOPE & CAPTURE & ELASTIC & NU & INELASTIC & FISSION & SUM \\
\hline U238 & 0.25 & 0.16 & 0.13 & 0.89 & 0.03 & 0.95 \\
\hline PU240 & 0.33 & 0.00 & 0.28 & 0.02 & 0.26 & 0.51 \\
\hline PU241 & 0.05 & 0.00 & 0.01 & 0.00 & 0.40 & 0.40 \\
\hline PU239 & 0.25 & 0.02 & 0.15 & 0.08 & 0.20 & 0.37 \\
\hline PU238 & 0.02 & 0.00 & 0.04 & 0.01 & 0.34 & 0.34 \\
\hline PU242 & 0.06 & 0.00 & 0.02 & 0.01 & 0.08 & 0.11 \\
\hline NI58 & 0.10 & 0.00 & 0.00 & 0.02 & 0.00 & 0.11 \\
\hline FE56 & 0.10 & 0.02 & 0.00 & 0.02 & 0.00 & 0.10 \\
\hline O16 & 0.01 & 0.09 & 0.00 & 0.00 & 0.00 & 0.09 \\
\hline NA23 & 0.00 & 0.05 & 0.00 & 0.07 & 0.00 & 0.09 \\
\hline AM241 & 0.06 & 0.00 & 0.02 & 0.01 & 0.04 & 0.07 \\
\hline CM245 & 0.00 & 0.00 & 0.01 & 0.00 & 0.06 & 0.06 \\
\hline CM244 & 0.04 & 0.00 & 0.02 & 0.00 & 0.02 & 0.05 \\
\hline FE54 & 0.03 & 0.00 & 0.00 & 0.01 & 0.00 & 0.03 \\
\hline AM242M & 0.00 & 0.00 & 0.00 & 0.00 & 0.03 & 0.03 \\
\hline SUM & 0.52 & 0.20 & 0.35 & 0.90 & 0.63 & 1.28 \\
\hline
\end{tabular}

Table IX. EFR: keff Uncertainty Difference (\%) between AFCI1.2 and BOLNA (major contributions)

\begin{tabular}{|c|c|c|c|c|c|c|}
\hline ISOTOPE & CAPTURE & ELASTIC & NU & INELASTIC & FISSION & SUM \\
\hline PU238 & 0.00 & 0.00 & -0.06 & 0.00 & 0.21 & 0.18 \\
\hline O16 & -0.25 & 0.04 & 0.00 & -0.03 & 0.00 & -0.17 \\
\hline FE56 & 0.04 & 0.00 & 0.00 & -0.16 & 0.00 & -0.09 \\
\hline PU240 & 0.08 & 0.00 & 0.00 & 0.01 & 0.04 & 0.07 \\
\hline SUM & -0.06 & 0.01 & 0.01 & 0.00 & 0.10 & 0.02 \\
\hline
\end{tabular}


Report on INL Activities for Uncertainty Reduction Analysis of FY10

September 2010

Table X. GFR: keff Uncertainty (\%)

\begin{tabular}{|c|c|c|c|c|c|c|}
\hline ISOTOPE & CAPTURE & ELASTIC & NU & INELASTIC & FISSION & SUM \\
\hline U238 & 0.29 & 0.14 & 0.16 & 1.50 & 0.04 & 1.54 \\
\hline PU241 & 0.08 & 0.00 & 0.03 & 0.01 & 0.80 & 0.80 \\
\hline PU238 & 0.03 & 0.00 & 0.06 & 0.01 & 0.54 & 0.54 \\
\hline AM241 & 0.26 & 0.00 & 0.09 & 0.03 & 0.26 & 0.38 \\
\hline PU240 & 0.20 & 0.00 & 0.20 & 0.02 & 0.21 & 0.36 \\
\hline PU239 & 0.22 & 0.01 & 0.13 & 0.07 & 0.15 & 0.30 \\
\hline PU242 & 0.15 & 0.00 & 0.05 & 0.03 & 0.22 & 0.27 \\
\hline SI28 & 0.11 & 0.08 & 0.00 & 0.04 & 0.00 & 0.14 \\
\hline CM245 & 0.00 & 0.00 & 0.02 & 0.00 & 0.13 & 0.13 \\
\hline CM244 & 0.08 & 0.00 & 0.04 & 0.00 & 0.05 & 0.10 \\
\hline CGRA & 0.00 & 0.05 & 0.00 & 0.07 & 0.00 & 0.09 \\
\hline AM243 & 0.05 & 0.00 & 0.01 & 0.02 & 0.04 & 0.07 \\
\hline NP237 & 0.04 & 0.00 & 0.01 & 0.02 & 0.05 & 0.07 \\
\hline ZR92 & 0.03 & 0.04 & 0.00 & 0.01 & 0.00 & 0.05 \\
\hline ZR91 & 0.04 & 0.03 & 0.00 & 0.00 & 0.00 & 0.05 \\
\hline SUM & 0.54 & 0.18 & 0.31 & 1.51 & 1.07 & 1.96 \\
\hline
\end{tabular}

Table XI. GFR: keff Uncertainty Difference (\%) between AFCI1.2 and BOLNA (major contributions)

\begin{tabular}{|c|c|c|c|c|c|c|}
\hline ISOTOPE & CAPTURE & ELASTIC & NU & INELASTIC & FISSION & SUM \\
\hline PU238 & 0.00 & 0.00 & -0.09 & 0.01 & 0.33 & 0.29 \\
\hline CGRA & -0.01 & -0.26 & 0.00 & 0.02 & 0.00 & -0.23 \\
\hline SI28 & 0.11 & 0.08 & 0.00 & 0.04 & 0.00 & 0.14 \\
\hline SUM & -0.04 & -0.16 & -0.01 & 0.07 & 0.11 & 0.08 \\
\hline
\end{tabular}

Table XII. LFR: keff Uncertainty (\%)

\begin{tabular}{|c|c|c|c|c|c|c|}
\hline ISOTOPE & CAPTURE & ELASTIC & NU & INELASTIC & FISSION & SUM \\
\hline PU238 & 0.04 & 0.00 & 0.10 & 0.01 & 0.93 & 0.93 \\
\hline U238 & 0.17 & 0.08 & 0.10 & 0.81 & 0.03 & 0.84 \\
\hline PU240 & 0.40 & 0.00 & 0.38 & 0.06 & 0.32 & 0.64 \\
\hline PU241 & 0.07 & 0.00 & 0.02 & 0.01 & 0.61 & 0.61 \\
\hline PB206 & 0.08 & 0.03 & 0.00 & 0.33 & 0.00 & 0.34 \\
\hline PU239 & 0.17 & 0.01 & 0.12 & 0.11 & 0.20 & 0.31 \\
\hline PB208 & 0.10 & 0.22 & 0.00 & 0.06 & 0.00 & 0.25 \\
\hline CM245 & 0.00 & 0.00 & 0.02 & 0.00 & 0.23 & 0.23 \\
\hline PU242 & 0.10 & 0.00 & 0.04 & 0.02 & 0.18 & 0.21 \\
\hline PB207 & 0.09 & 0.03 & 0.00 & 0.10 & 0.00 & 0.14 \\
\hline FE56 & 0.11 & 0.05 & 0.00 & 0.02 & 0.00 & 0.12 \\
\hline AM241 & 0.08 & 0.00 & 0.02 & 0.02 & 0.06 & 0.11 \\
\hline CM244 & 0.07 & 0.00 & 0.04 & 0.01 & 0.05 & 0.09 \\
\hline AM242M & 0.01 & 0.00 & 0.00 & 0.00 & 0.06 & 0.06 \\
\hline ZR92 & 0.04 & 0.03 & 0.00 & 0.03 & 0.00 & 0.06 \\
\hline SUM & 0.54 & 0.25 & 0.43 & 0.90 & 1.21 & 1.68 \\
\hline
\end{tabular}


Table XIII. LFR: keff Uncertainty Difference (\%) between AFCI1.2 and BOLNA (major contributions)

\begin{tabular}{|c|c|c|c|c|c|c|}
\hline ISOTOPE & CAPTURE & ELASTIC & NU & INELASTIC & FISSION & SUM \\
\hline PU238 & 0.00 & 0.00 & -0.13 & 0.01 & 0.58 & 0.52 \\
\hline B10 & -0.27 & -0.02 & 0.00 & 0.00 & 0.00 & -0.27 \\
\hline PB206 & -0.03 & 0.01 & 0.00 & 0.18 & 0.00 & 0.16 \\
\hline FE56 & 0.06 & 0.03 & 0.00 & -0.22 & 0.00 & -0.12 \\
\hline PB208 & 0.06 & 0.09 & 0.00 & 0.02 & 0.00 & 0.11 \\
\hline PU240 & 0.15 & 0.00 & 0.01 & 0.03 & 0.01 & 0.10 \\
\hline SUM & 0.01 & 0.10 & -0.03 & 0.04 & 0.37 & 0.28 \\
\hline
\end{tabular}

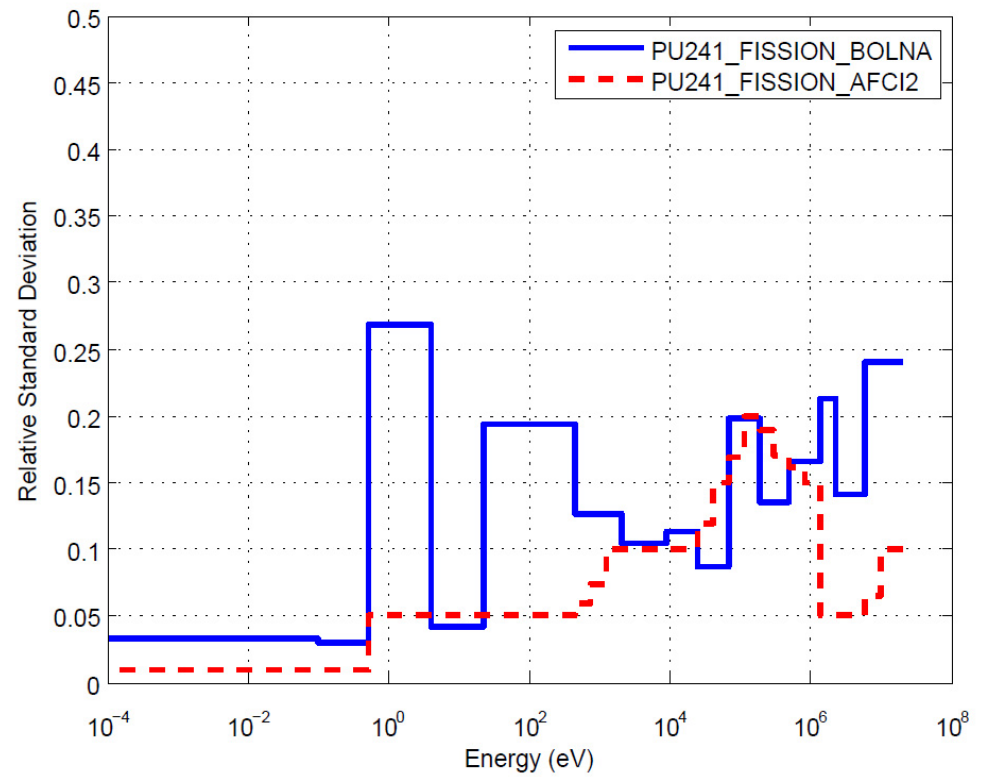

Figure 1. Relative Standard Deviation of Pu241 Fission Cross-sections in BOLNA and AFCI 1.2

The major contributions to the difference between the two covariance data sets are the Pu238 fission cross section uncertainty (much higher uncertainty values in AFCI 1.2, see figure 2) and the inelastic cross section of Fe56 (much smaller in AFCI 1.2, see Figure 3). These are certainly issues that need further analysis. 


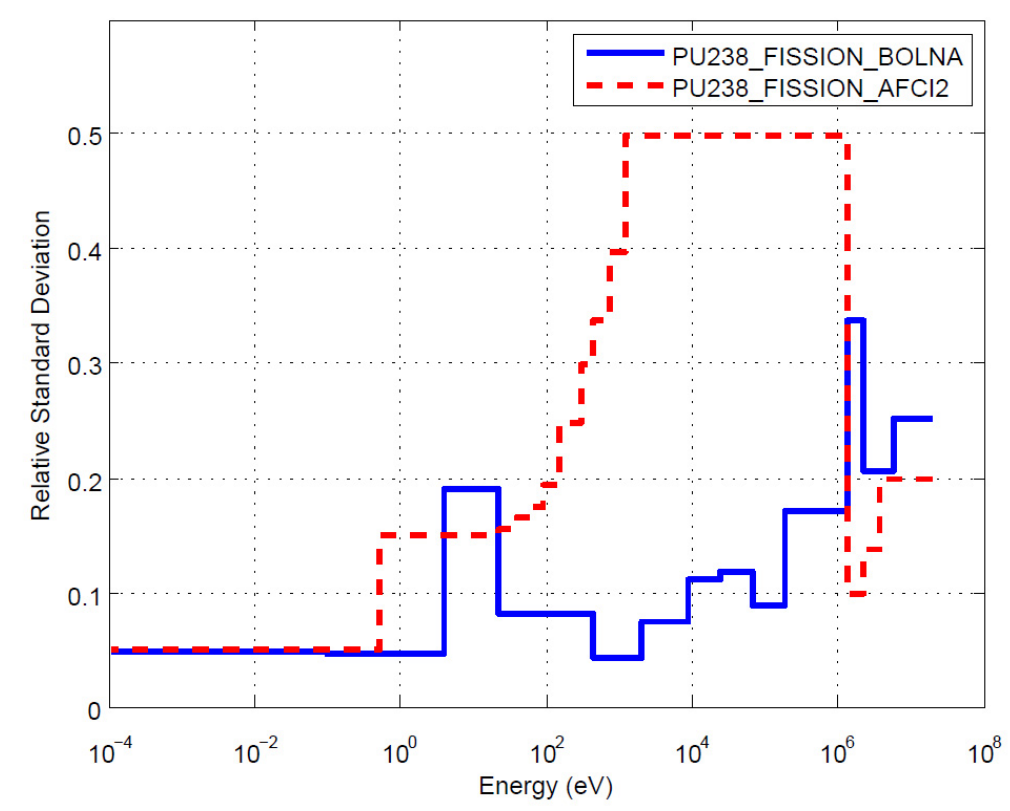

Figure 2. Relative Standard Deviation of Pu238 Fission Cross-sections in BOLNA and AFCI 1.2

The AFCI 1.2 uncertainty data for Pu238 are based on a comparative analysis done by Maslov, as indicated in Ref. 4. He compared evaluations in major data libraries and considered his own results and experimental data. Estimated uncertainties are based on difference with ENDF/B VII.0.

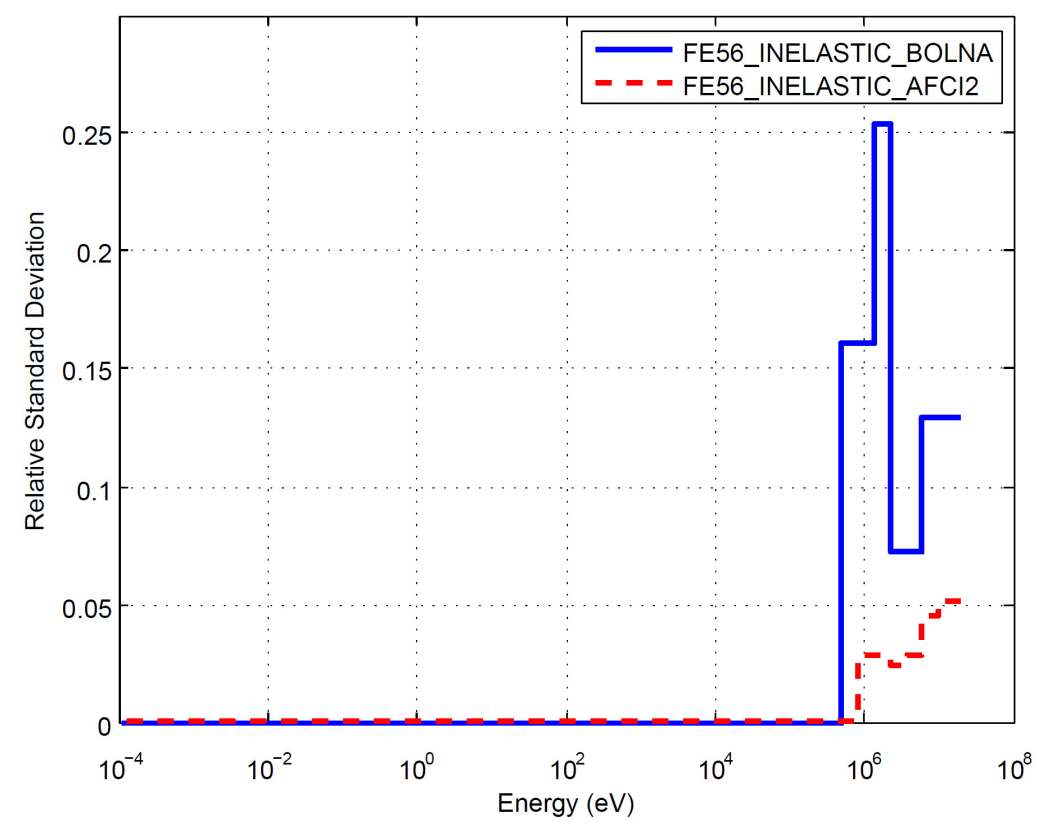

Figure 3. Relative Standard Deviation of Fe56 Inelastic Scattering Cross-sections in BOLNA and AFCI 1.2

As for minor actinides, their uncertainties continue to play an important role when the MA content in the core fuel is high (i.e. ADMAB and SFR). However, the AFCI 1.2 values confirm the previous analysis with BOLNA in the case of $\mathrm{Cm} 245$ (see Figure 4, where fission cross section uncertainties are compared) 
and Am241, but give a lower uncertainty associated to the fission of $\mathrm{Cm} 244$ (see figure 5, relative to the fission cross section uncertainties in both covariance data sets).

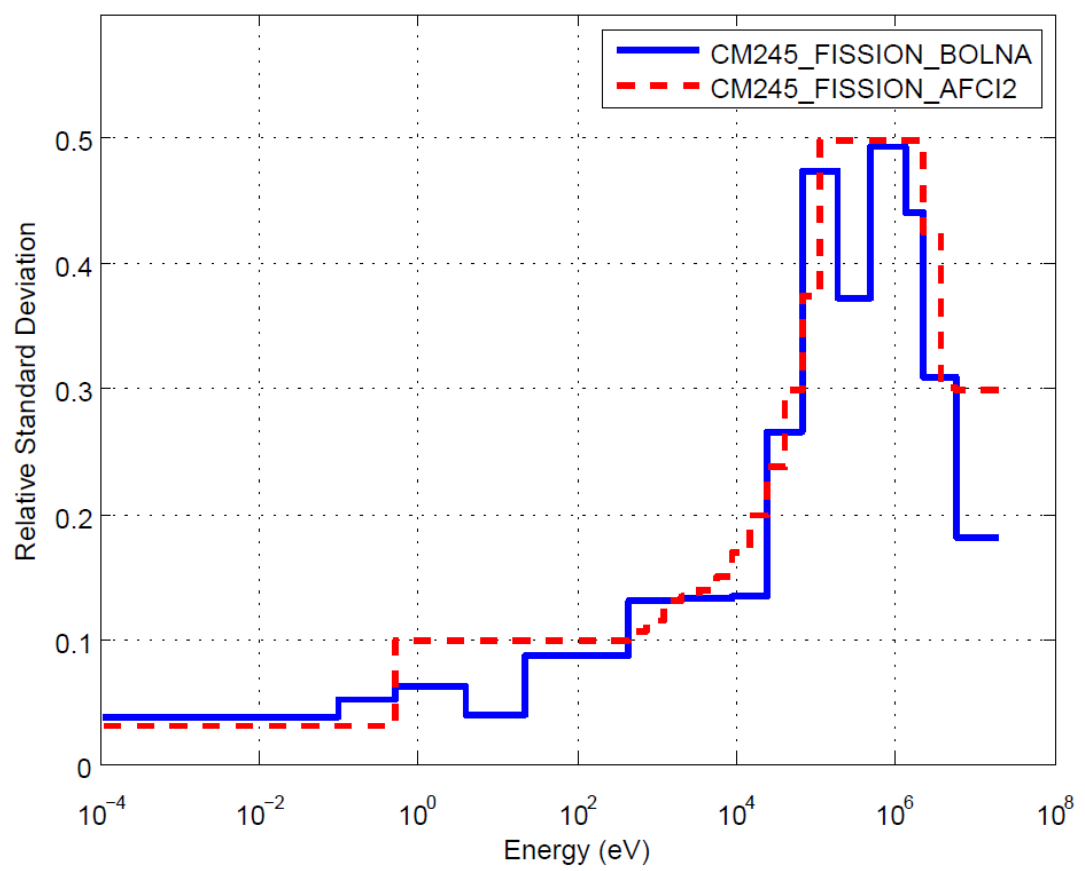

Figure 4. Relative Standard Deviation of Cm245 Fission Cross-sections in BOLNA and AFCI 1.2

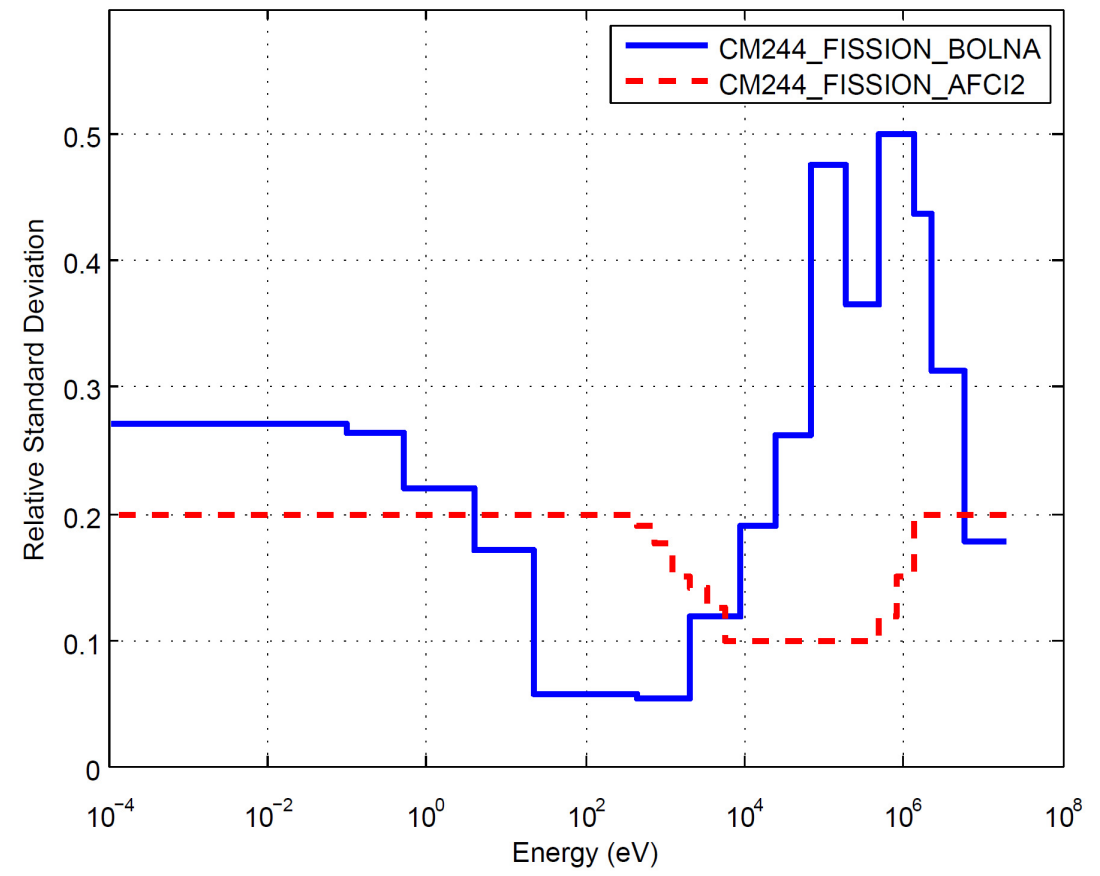

Figure 5. Relative Standard Deviation of Cm244 Fission Cross-sections in BOLNA and AFCI 1.2

Finally in the case of GFR it is interesting to point out the impact of the strong uncertainty reduction in AFCI 1.2 of the $\mathrm{C}$ elastic cross section (see figure 6 for the corresponding uncertainties comparison in 
AFCI 1.2 and BOLNA). The AFCI 1.2 uncertainty values are a LANL estimate. In the energy range 1 $\mathrm{keV}-1.8 \mathrm{MeV}$, the $\mathrm{C}$ elastic cross section is a standard, and the latest evaluation gives uncertainties in the range $\sim 0.5-0.9 \%$.

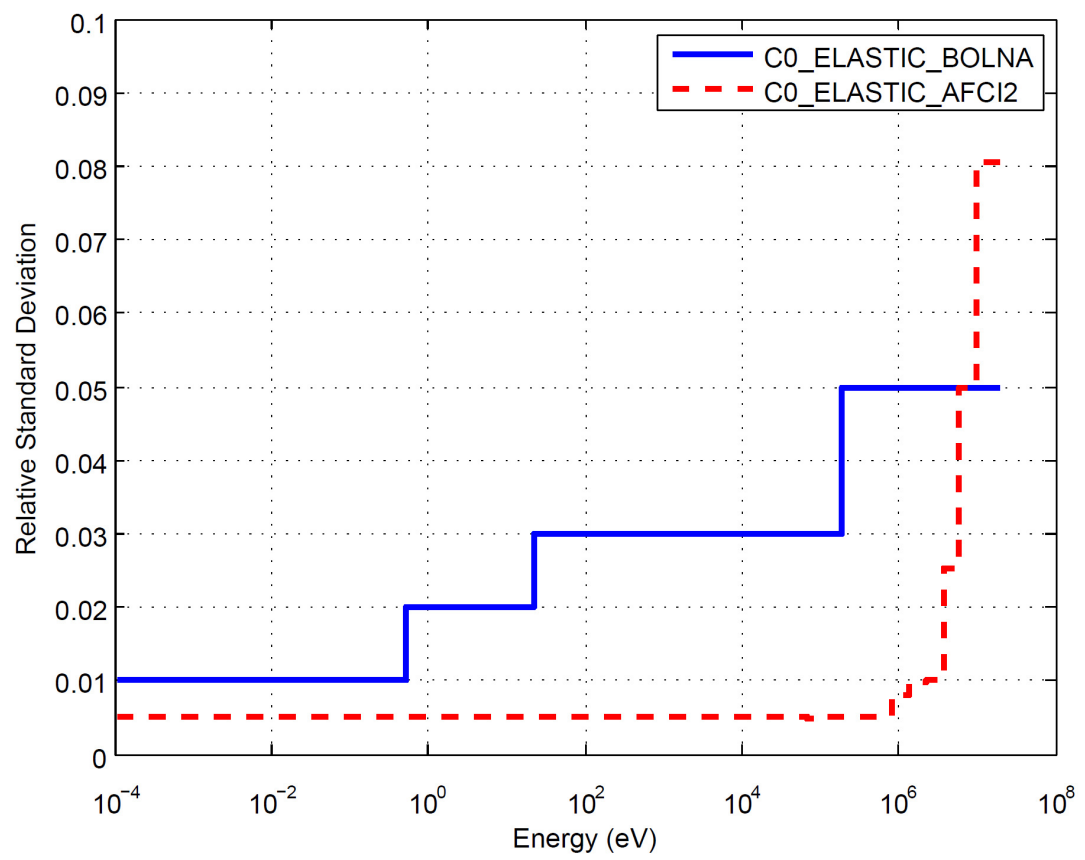

Figure 6. Relative Standard Deviation of C Elastic Scattering Cross-sections in BOLNA and AFCI 1.2

Table XIV. SFR: Coolant-voided Reactivity Uncertainty (\%) by Isotope (Full AFCI 1.2 Correlation Data)

\begin{tabular}{|c|c|c|c|c|c|c|}
\hline ISOTOPE & CAPTURE & ELASTIC & NU & INELASTIC & FISSION & SUM \\
\hline PU238 & 0.67 & 0.04 & 0.36 & 0.17 & 8.78 & 8.82 \\
\hline NA23 & 0.35 & 1.02 & 0.00 & 4.82 & 0.00 & 4.94 \\
\hline FE56 & 1.43 & 4.46 & 0.00 & 0.39 & 0.00 & 4.70 \\
\hline PU241 & 0.59 & 0.04 & 0.14 & 0.20 & 3.98 & 4.04 \\
\hline PU240 & 1.27 & 0.11 & 2.46 & 0.49 & 2.46 & 3.74 \\
\hline PU242 & 2.37 & 0.04 & 0.60 & 0.20 & 2.20 & 3.29 \\
\hline AM242M & 0.71 & 0.02 & 0.26 & 0.21 & 2.45 & 2.57 \\
\hline CM244 & 1.99 & 0.02 & 0.76 & 0.08 & 0.77 & 2.27 \\
\hline PU239 & 1.13 & 0.34 & 1.07 & 0.65 & 0.91 & 1.94 \\
\hline U238 & 0.76 & 0.60 & 0.10 & 1.57 & 0.02 & 1.85 \\
\hline CM245 & 0.05 & 0.00 & 0.26 & 0.03 & 1.05 & 1.09 \\
\hline AM241 & 0.78 & 0.02 & 0.19 & 0.20 & 0.44 & 0.94 \\
\hline FE54 & 0.33 & 0.85 & 0.00 & 0.06 & 0.00 & 0.91 \\
\hline AM243 & 0.64 & 0.02 & 0.05 & 0.26 & 0.25 & 0.74 \\
\hline NP237 & 0.64 & 0.01 & 0.05 & 0.20 & 0.24 & 0.72 \\
\hline SUM & 4.27 & 4.81 & 2.91 & 5.20 & 10.63 & 13.78 \\
\hline
\end{tabular}


As for the other parameters considered in the study of Subgroup 26 and reported in [1], the only significant new effect is related to the very high uncertainty of the Pu238 fission cross section in AFCI 1.2. In fact an uncertainty of $\sim 9 \%$ is observed in the case of the Na void coefficient in the SFR system, see table XIV.

Finally, the new AFCI 1.2 covariance data set has some cross correlations between cross sections for a few isotopes and reactions (see Table XV). Their effect is very small at present. However, the generalization of this type of data in future versions of the covariance data sets will improve their quality and reliability.

Table XV. List of Isotopes with Cross-Reaction Correlations in AFCI 1.2

\begin{tabular}{|c|c|c|c|c|c|}
\hline B10 & ELASTIC x INELASTIC & GD155 & ELASTIC x CAPTURE & U233 & ELASTIC $\times \mathrm{N}->2 \mathrm{~N}$ \\
\hline B10 & INELASTIC x CAPTURE & GD157 & ELASTIC x CAPTURE & U233 & ELASTIC x FISSION \\
\hline B11 & ELASTIC x INELASTIC & GD160 & ELASTIC x CAPTURE & U233 & ELASTIC $\times$ CAPTURE \\
\hline B11 & ELASTIC $\times \mathrm{N}->2 \mathrm{~N}$ & $\mathrm{H} 2$ & ELASTIC $\times \mathrm{N}->2 \mathrm{~N}$ & U233 & FISSION $\times$ CAPTURE \\
\hline B11 & ELASTIC $\times$ CAPTURE & LI7 & ELASTIC $\times$ INELASTIC & U235 & ELASTIC $\times$ INELASTIC \\
\hline BE9 & ELASTIC $\times N->2 N$ & MN55 & ELASTIC x INELASTIC & U235 & ELASTIC $\times \mathrm{N}->2 \mathrm{~N}$ \\
\hline BE9 & ELASTIC x CAPTURE & MN55 & ELASTIC $\times \mathrm{N}->2 \mathrm{~N}$ & U235 & ELASTIC x FISSION \\
\hline $\mathrm{C} 12$ & ELASTIC $\times$ INELASTIC & MN55 & ELASTIC x CAPTURE & U235 & ELASTIC $\times$ CAPTURE \\
\hline C12 & INELASTIC x CAPTURE & N15 & ELASTIC $\times$ INELASTIC & U235 & FISSION x CAPTURE \\
\hline CM246 & ELASTIC x INELASTIC & N15 & ELASTIC $\times \mathrm{N}->2 \mathrm{~N}$ & U238 & ELASTIC x INELASTIC \\
\hline CM246 & ELASTIC $\times \mathrm{N}->2 \mathrm{~N}$ & N15 & ELASTIC x CAPTURE & U238 & ELASTIC $\times \mathrm{N}->2 \mathrm{~N}$ \\
\hline CM246 & ELASTIC x FISSION & NA23 & ELASTIC x CAPTURE & U238 & ELASTIC x FISSION \\
\hline $\mathrm{CM} 246$ & ELASTIC x CAPTURE & NI58 & ELASTIC x CAPTURE & U238 & ELASTIC $\times$ CAPTURE \\
\hline CR52 & ELASTIC x CAPTURE & 016 & ELASTIC x INELASTIC & U238 & FISSION x CAPTURE \\
\hline CR53 & ELASTIC x CAPTURE & 016 & INELASTIC x N->2N & ZR90 & ELASTIC x INELASTIC \\
\hline F19 & ELASTIC x INELASTIC & 016 & INELASTIC x CAPTURE & ZR90 & ELASTIC $\times N->2 N$ \\
\hline F19 & ELASTIC $\times \mathrm{N}->2 \mathrm{~N}$ & PU239 & ELASTIC $\times$ INELASTIC & ZR90 & ELASTIC x CAPTURE \\
\hline F19 & INELASTIC x N->2N & PU239 & ELASTIC $\times \mathrm{N}->2 \mathrm{~N}$ & & \\
\hline F19 & ELASTIC x CAPTURE & PU239 & ELASTIC x FISSION & & \\
\hline FE56 & ELASTIC $x$ INELASTIC & PU239 & ELASTIC x CAPTURE & & \\
\hline FE56 & ELASTIC $\times \mathrm{N}->2 \mathrm{~N}$ & PU239 & FISSION x CAPTURE & & \\
\hline FE56 & INELASTIC x N->2N & TH232 & ELASTIC x FISSION & & \\
\hline FE56 & ELASTIC x CAPTURE & TH232 & ELASTIC x CAPTURE & & \\
\hline FE56 & INELASTIC x CAPTURE & TH232 & FISSION x CAPTURE & & \\
\hline FE56 & $\mathrm{N}->2 \mathrm{~N} \times$ CAPTURE & U233 & ELASTIC x INELASTIC & & \\
\hline
\end{tabular}

\subsection{Summary on uncertainty evaluation}

The results of the present investigation indicate that a careful analysis is still needed in order to define the most appropriate and effective strategy for data uncertainty reduction. It seems that, besides a further consolidation of the present covariance data libraries, a strategy of combined use of integral and differential measurements should be further pursued in order to meet future requirements. Efforts in this direction are underway (see e.g. Ref. 5), and a new Subgroup has been established by the WPEC of the 
NEA-NSC in order to evaluate and compare different approaches in the field of the so-called "statistical data adjustment" or "data assimilation" methods. The program of this new Subgroup (called "33"), is to inter-compare the statistical data adjustments performed simultaneously in different laboratories, starting from the same set of integral data and different cross section data sets. As for covariance data, the proposed exercise will have a first phase when all participants will use the same covariance data and a second phase when different covariance data sets will be used. The objective of the exercise is to verify at what extent a convergence of the adjusted data sets will be obtained. This type of outcome will greatly improve the perception of reliability of the adjusted data sets, in particular with respect to their respective domain of applicability. Moreover, the impact of different covariance data will be evaluated and the significance of having a set of data consistent with the original cross section libraries will be assessed. 


\section{EXPERIMENTAL ANALYSIS}

This section of the report presents the progress in the analysis of selected integral experiments using Monte Carlo code MCNP5 [6] and ERANOS code system [2] with ENDF/B-VII cross sections library.

\subsection{ZPPR-10A Benchmark for Reactivity Effects}

The ZPPR-10A was assembled as a part of the JUPITER-I series experiments in order to simulate the end-of-cycle configuration of 600MWe class of sodium-cooled MOX fueled FBR core. The ZPPR-10A core is a hexagonal shaped core consisting of a number of stainless steel drawers with small plates of depleted uranium, sodium (carbonate), iron oxide, depleted U3O8, stainless steel, and Pu-U-Mo alloy. The detailed reference core configuration is shown in Figure 1 [7].

The control rod worth was measured by replacing sodium plates filled in $3 \times 3$ arrays of drawers in several control rod positions (CRPs) with $50 \%$ B4C plates and $50 \%$ sodium plates and measuring the excess reactivity of the resulting configuration. The reference configuration for the sodium void worth measurements was constructed by replacing double column fuel (DCF) drawers in the reference critical configuration with single column fuel (SCF) drawers at 20 selected matrix positions in order to make it subcritical. Then, the sodium void worth was measured by creating voided zones in selected drawers.

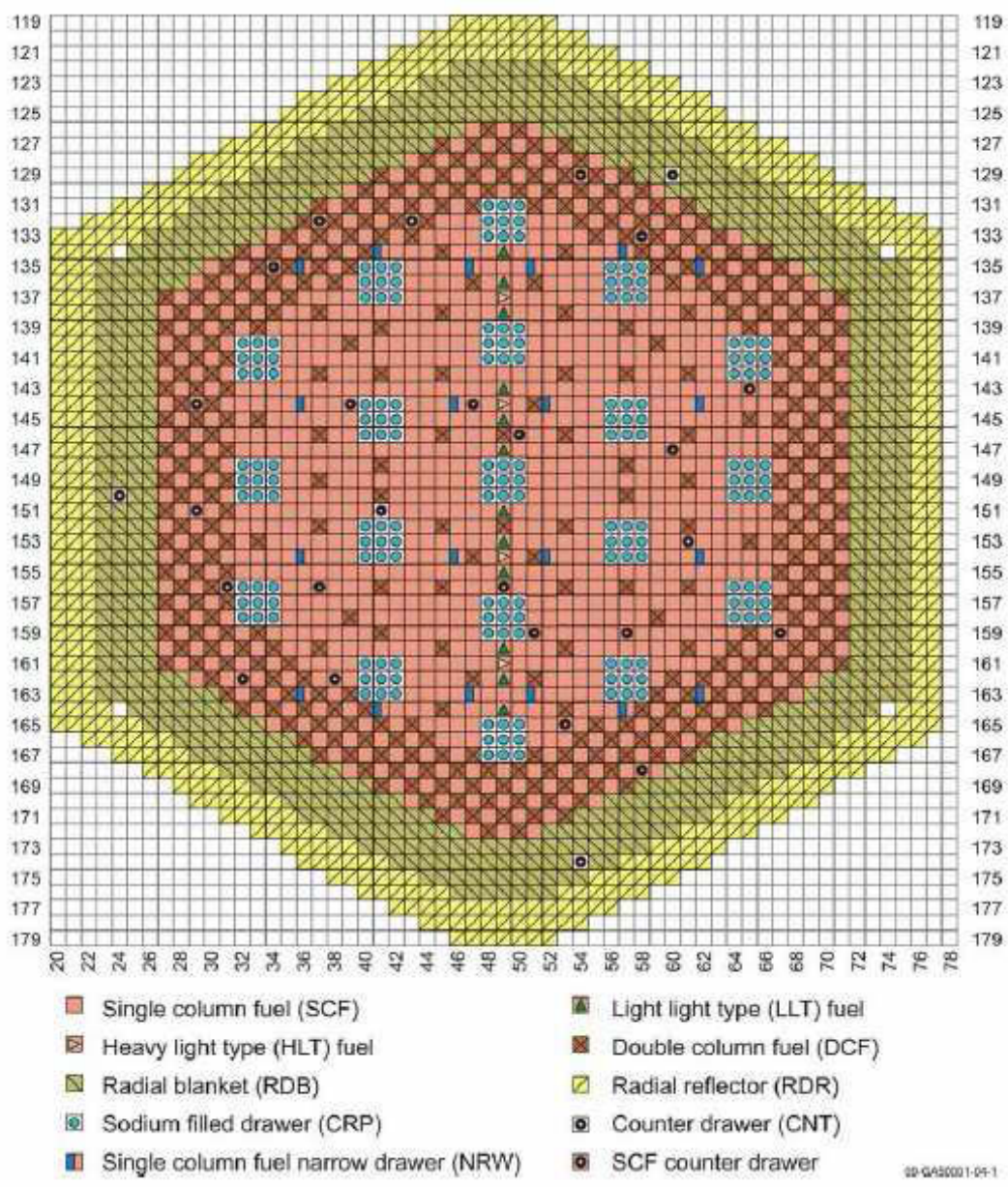

Figure 7: ZPPR-10A reference configuration (From Reference /2/). 
MCNP calculations were performed for total of eight reactivity measurements (four for control rod worth and four for sodium void worth) using as-built models from IRPhEP document [7]. Based on $k_{\text {eff }}$ 's obtained by MCNP calculations, the control rod worth were calculated by:

$$
\Delta \rho_{C R}=\frac{k_{r e f}-k_{r o d}}{k_{r e f} k_{r o d} \beta_{e f f}}
$$

where $k_{r e f}$ is the neutron multiplication factor of the reference configuration, $k_{r o d}$ is that of the rodded configuration, and $\beta_{\text {eff }}$ is the effective delayed neutron fraction, which was approximated by:

$$
\beta_{\text {eff }} \cong \frac{k_{\text {ref }}-k_{\text {prompt }}}{k_{\text {ref }}}
$$

where $k_{\text {prompt }}$ is the multiplication factor calculated with only prompt neutrons. All multiplication factors here contain statistical errors. Thus, these statistical errors must be propagated into the error of control rod worth. This can be formulated as:

$$
\sigma_{\Delta \rho_{C R}}=\sqrt{\left(\frac{1}{k_{r e f}^{2} \beta_{e f f}}\right)^{2} \sigma_{k_{r e f}}^{2}+\left(\frac{1}{k_{r o d}^{2} \beta_{e f f}}\right)^{2} \sigma_{k_{r o d}}^{2}+\left(\frac{1}{k_{r e f} \beta_{e f f}^{2}}-\frac{1}{k_{r o d} \beta_{e f f}^{2}}\right)^{2} \sigma_{\beta_{e f f}}^{2}},
$$

where

$$
\sigma_{\beta_{\text {eff }}}=\frac{k_{\text {prompt }}}{k_{\text {ref }}} \sqrt{\left(\frac{\sigma_{k_{\text {prompt }}}}{k_{\text {prompt }}}\right)^{2}+\left(\frac{\sigma_{k_{\text {ref }}}}{k_{\text {ref }}}\right)^{2}} .
$$

Similar formulations are used for sodium void reactivity calculations.

Tables XVI and XVII show experimental control rod worth and sodium void reactivity of each case, respectively, along with their $\mathrm{C} / \mathrm{E}$ ratios based on our MCNP calculations. The calculated delayed neutron fraction is shown in the parenthesis at the bottom-left corner of each table. Comparisons were made with uncorrelated experimental values since the ZPPR-10A core was modeled explicitly. As seen in Tables, calculated control rod worth results have excellent agreement with experimental values, and results of all cases have similar quality of agreement. On the other hand, calculated values of sodium void reactivity have different quality of agreement. The magnitude of discrepancy becomes larger as the number of voiding zones becomes small. One of reasons could be due to the small order of reactivity ( $\sim 50$ cents) which requires much smaller statistical errors of $k_{\text {eff }}$ from MC calculations than those for control rod worth calculations in order to obtain statistically reliable reactivity.

Table XVI: Comparison of ZPPR-10A Control Rod Worth

\begin{tabular}{|c|c|c|}
\hline Radial Control Rod Position & Experiment [\$] /2/ & C/E \\
\hline Central Control Rod & $2.61 \pm 0.03$ & $1.0496 \pm 0.0385$ \\
\hline CR's 2-7, 6 rods in Ring 4 & $13.25 \pm 0.14$ & $1.0608 \pm 0.0368$ \\
\hline CR's 8-19, 12 rods in Ring 7 & $21.09 \pm 0.31$ & $1.0440 \pm 0.0377$ \\
\hline CR's 8, 10, 12, 14, 16, 18 in corners of Ring 7 & $9.54 \pm 0.11$ & $1.0501 \pm 0.0368$ \\
\hline
\end{tabular}

$\left(\beta_{\text {eff }}=0.00343323 \pm 0.00011305\right)$ 
Table XVII: Comparison of ZPPR-10A Sodium Void Reactivity.

\begin{tabular}{|c|c|c|}
\hline Voiding Zones & Experiment [cents] /2/ & C/E \\
\hline 88 drawers, 8 inches per half & $22.26 \pm 0.26$ & $1.2252 \pm 0.0569$ \\
\hline 172 drawers, 8 inches per half & $42.64 \pm 0.46$ & $1.0035 \pm 0.0335$ \\
\hline 172 drawers, 16 inches per half & $55.15 \pm 0.61$ & $1.0411 \pm 0.0317$ \\
\hline 172 drawers, 20 inches per half & $46.73 \pm 0.52$ & $0.9921 \pm 0.0313$ \\
\hline
\end{tabular}

$\left(\beta_{\text {eff }}=0.00343315 \pm 0.00004252\right)$

\section{$3.2 \quad$ ZPPR-9}

The ZPPR-9 experiments were also conducted as a part of JUPITER program in order to provide integral reactor parameters for conventional mixed-oxide-fueled two-zone liquid metal fast breeder reactors (LMFBRs) of about 650 MWe. The ZPPR-9 assembly is a cylindrical core consisting of two clean homogeneous zones. There is no control-rod position. A simplified cylindrical model was developed for both MCNP and ERANOS deterministic calculations. A diagram of this model is shown in Figure 8 .

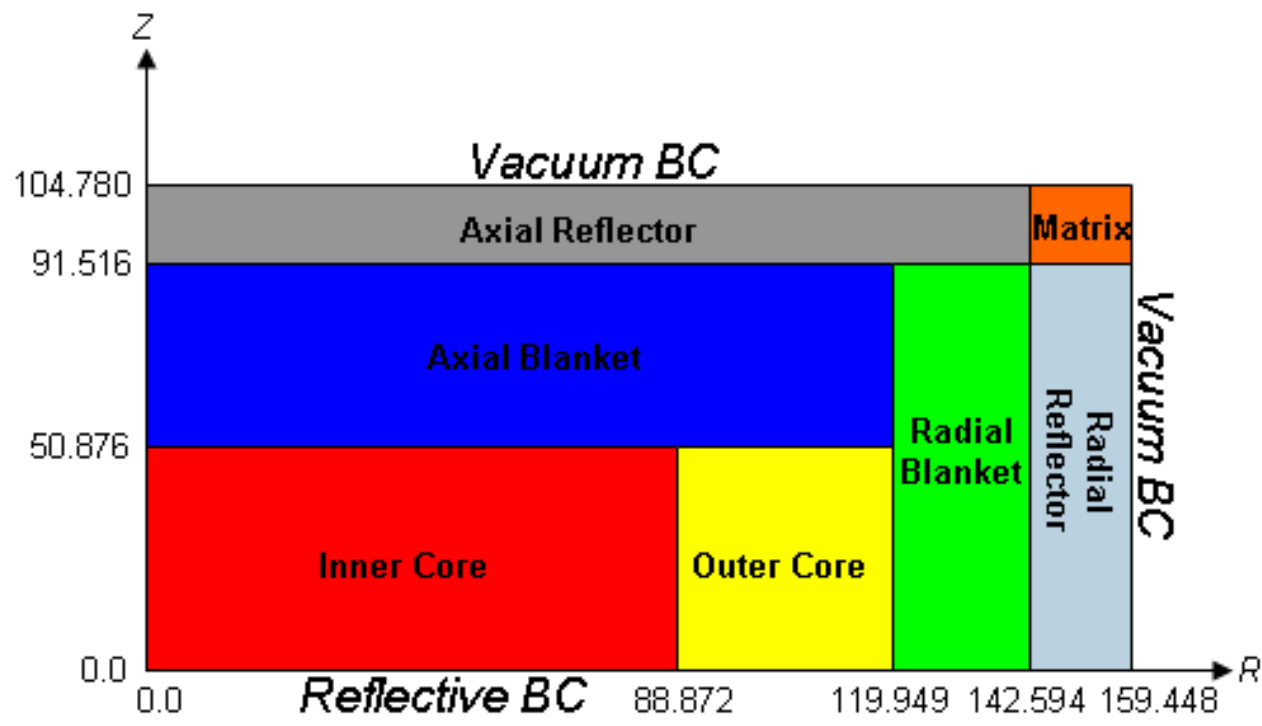

Figure 8: RZ Model of ZPPR-9 Core

Calculations of keff were performed using MC (MCNP) and SN (ERANOS) methods. For SN calculations, we utilized S4 quadratures with both P1 and P3 scattering expansions to see the possible effect of anisotropic scattering. Table XVIII shows the comparison of keff for ZPPR-9 models. The reference value shown here is the correlated value based on calculations performed by JAEA using JENDL library. Thus, it was expected to have some recognizable discrepancies from calculated values based on ENDF/B-VII. The difference between MCNP and ERANOS results is much smaller (less than $200 \mathrm{pcm}$ ) than the discrepancy from the reference value. In this respect, both models are consistent. There is a negligible effect caused by the difference in the order of scattering expansion. However, the effect can be significant when we analyze spectral indices at selected locations. The analysis of the spectral indices will be done in the next fiscal year. 
Table XVIII: Comparison of $\boldsymbol{k}_{\text {eff }}$ for ZPPR-9 Models

\begin{tabular}{|c|c|c|c|c|}
\hline & Reference & MCNP5 & $\begin{array}{c}\text { ERANOS } \\
\text { (33-group, S4P1) }\end{array}$ & $\begin{array}{c}\text { ERANOS } \\
\text { (33-group, S4P3) }\end{array}$ \\
\hline$k_{\text {eff }}$ & $0.99215( \pm 153 \mathrm{pcm})$ & $0.98656( \pm 14 \mathrm{pcm})$ & 0.98830 & 0.98840 \\
\hline
\end{tabular}

\subsection{ZPR6-7 Spectral indices}

ZPR 6-7 is a large cylindrical assembly surrounded by a thick depleted-uranium reflector based on mixed $\mathrm{Pu}-\mathrm{U}$ oxide fuels. There were two principal core configuration established for the ZPR6-7 program. Those were the uniform core loading and high ${ }^{240} \mathrm{Pu}$-zone core loading [7]. The former had a relatively uniform core composition. A central zone of 61 matrix locations in each half of the assembly was defined as the exact core. This exact core region had the same unit cell and the same average composition as the outer core, but the plates used in the exact core were those for which knowledge of material properties was most precise. The latter configuration was a variant of the uniform core. The plutonium in the standard $\mathrm{Pu}-\mathrm{U}-\mathrm{Mo}$ fuel plates used in the uniform core contains $11 \% \mathrm{Pu} 240$. The high Pu240 zone was built by replacing all of the $\mathrm{Pu}-\mathrm{U}-\mathrm{Mo}$ plates in the exact core region of the uniform core with $\mathrm{Pu}-\mathrm{U}-\mathrm{Mo}$ plates containing 27\% Pu240 in the plutonium component. The high Pu240 zone had a composition closer to that in an LMFBR core with high burnup [7].

In the last fiscal year, comparisons of $k_{\text {eff }}$ and spectral indices were performed utilizing detailed geometry models. The comparison of $k_{\text {eff }}$ had shown that the use of ENDF/B-VII did not contribute for reducing the discrepancy from the experimental result. This discrepancy was caused mainly due to the accuracy of our models. Therefore, we have decided to use detailed models from References 7 and 8 . Table XIX shows the comparison of $k_{\text {eff }}$ obtained with new and old models. As we see, results from new models were much closer to reference values than old ones.

Table XIX: Comparison of $\boldsymbol{k}_{\text {eff }}$ calculated with detailed ZPR6-7 models.

\begin{tabular}{|c|c|c|c|}
\hline Assembly & Reference /2/ & $\begin{array}{c}\text { MCNP5 } \\
\text { (old models) }\end{array}$ & $\begin{array}{c}\text { MCNP5 } \\
\text { (new models /2/) }\end{array}$ \\
\hline Uniform core loading & $1.00051 \pm 0.00087$ & $0.99796 \pm 0.00007$ & $1.00094 \pm 0.00007$ \\
\hline $\begin{array}{c}\text { High }{ }^{240} \text { Pu-zone core } \\
\text { loading }\end{array}$ & $1.0008 \pm 0.0009$ & $0.99240 \pm 0.00007$ & $1.00017 \pm 0.00011$ \\
\hline
\end{tabular}

The cell averaged spectral indices shown in the last year's report were calculated based on the volume weighted approach over each fuel plate at the central drawer (Figure 9). However, some of spectral indices showed large discrepancies (in particular, capture-to-fission ratio of U238). This indicated that the volume weighted approach was inappropriate. Therefore, we have utilized the atomic density weighted approach given by:

Reaction rate of Isotope $n=\frac{\sum_{i=1}^{3} R_{i}^{n} A_{i}^{n}}{\sum_{i=1}^{3} A_{i}^{n}}$ 
where $R_{i}^{n}$, and $A_{i}^{n}$ refer to reaction rate and atomic density of Isotope $n$ at Fuel plate $i$, respectively. Calculated results are compared in Table XX. More accurate solutions have been obtained by the atomic density weighted approach.

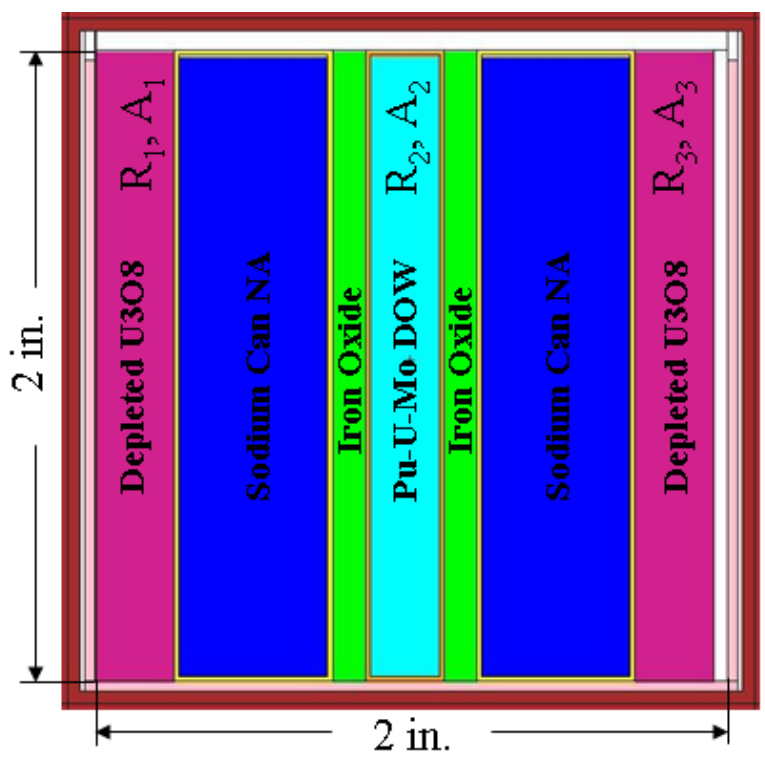

Figure 9: ZPPR6-7 central drawer.

Table XX: Comparison of spectral indices averaged over the central $2 \times 2 \times 2$ inch box in ZPR6-7 core

\begin{tabular}{|c|c|c|c|}
\hline Spectral Index & Experiment & C/E (Volume weighted) & $\begin{array}{c}\text { C/E (Atomic density } \\
\text { weighted) }\end{array}$ \\
\hline$\left.\left.\sigma_{\mathrm{f}}{ }^{235} \mathrm{U}\right) / \sigma_{\mathrm{f}}{ }^{239} \mathrm{Pu}\right)$ & $1.0599 \pm 0.0223$ & $1.0317 \pm 0.0224$ & $1.0376 \pm 0.0227$ \\
\hline$\sigma_{\mathrm{f}}\left({ }^{238} \mathrm{U}\right) / \sigma_{\mathrm{f}}\left({ }^{235} \mathrm{U}\right)$ & $0.0223 \pm 0.0007$ & $0.9148 \pm 0.0301$ & $1.0045 \pm 0.0328$ \\
\hline$\left.\sigma_{\mathrm{f}}\left({ }^{238} \mathrm{U}\right) / \sigma_{\mathrm{f}}{ }^{239} \mathrm{Pu}\right)$ & $0.0233 \pm 0.0007$ & $0.9571 \pm 0.0300$ & $1.0601 \pm 0.0344$ \\
\hline$\left.\sigma_{\mathrm{n}, \mathrm{r}}\left({ }^{238} \mathrm{U}\right) / \sigma_{\mathrm{f}}{ }^{235} \mathrm{U}\right)$ & $0.1323 \pm 0.0032$ & $1.0227 \pm 0.0257$ & $1.0098 \pm 0.0252$ \\
\hline$\left.\left.\sigma_{\mathrm{n}, \gamma}{ }^{238} \mathrm{U}\right) / \sigma_{\mathrm{f}}{ }^{239} \mathrm{Pu}\right)$ & $0.1399 \pm 0.0032$ & $1.0572 \pm 0.0252$ & $1.0500 \pm 0.0251$ \\
\hline$\left.\sigma_{\mathrm{n}, \gamma}\left({ }^{238} \mathrm{U}\right) / \sigma_{\mathrm{f}}{ }^{238} \mathrm{U}\right)$ & $5.8903 \pm 0.1897$ & $1.1243 \pm 0.0381$ & $1.0111 \pm 0.0342$ \\
\hline
\end{tabular}

\subsection{PROFIL-1 Analysis}

The PROFIL-1 irradiation experiment was performed in the Phoenix reactor. The experiment provides a powerful source of information for the nuclear data adjustment for major and minor actinides and several fission products. In FY2009, the accuracy of PROFIL-1 model was validated by comparing initial $k_{\text {eff }}$ and axial flux distribution to their experimental values. In order to perform three-dimensional burn-up Monte Carlo calculations, it is important to obtain accurate and statistically reliable one-group cross sections for each irradiated sample that are to be used for solving Bateman equations. However, it is extremely difficult to obtain statistically reliable tally results since the size of each sample is very small $\left(\sim 0.06 \mathrm{~cm}^{3}\right)$, and some of reactions (e.g., $\left.(\mathrm{n}, 2 \mathrm{n}),(\mathrm{n}, 3 \mathrm{n})\right)$ are caused by very fast neutrons $(5 \mathrm{MeV} \sim)$ which 
are usually not well populated. Moreover, it is not straightforward to perform variance reduction in criticality calculations. Thus, we came up with a calculation procedure that uses MCNP's surface source capability (Figure 10). In this approach, first, a full-core criticality calculation is performed with the surface source write (SSW) card in order to generate the binary source file containing the surface and fission volume sources around and in the irradiated fuel samples, respectively. This source file is used to perform the fixed source calculation with the reduced geometry modeling only the irradiated fuel pin. The fixed source calculation can be performed with only the recorded particles from the full-core criticality calculation. If the number of recorded source particles is small, then it is not feasible to obtain statistically reliable solutions even with variance reduction techniques. In order to resolve this problem, we wrote a program that duplicates the recorded information of source particles. However, the number of duplications is limited because adding additional source particles enlarges the size of the source file. To address this issue, we performed several fixed source calculations by skipping random numbers corresponding to the number of histories for each run. After finishing all fixed source calculations, the solutions were collected, and then the batch statistics was taken.

Tables XXI-XXXIII show the calculated one-group cross sections for selected samples by this presented procedure.

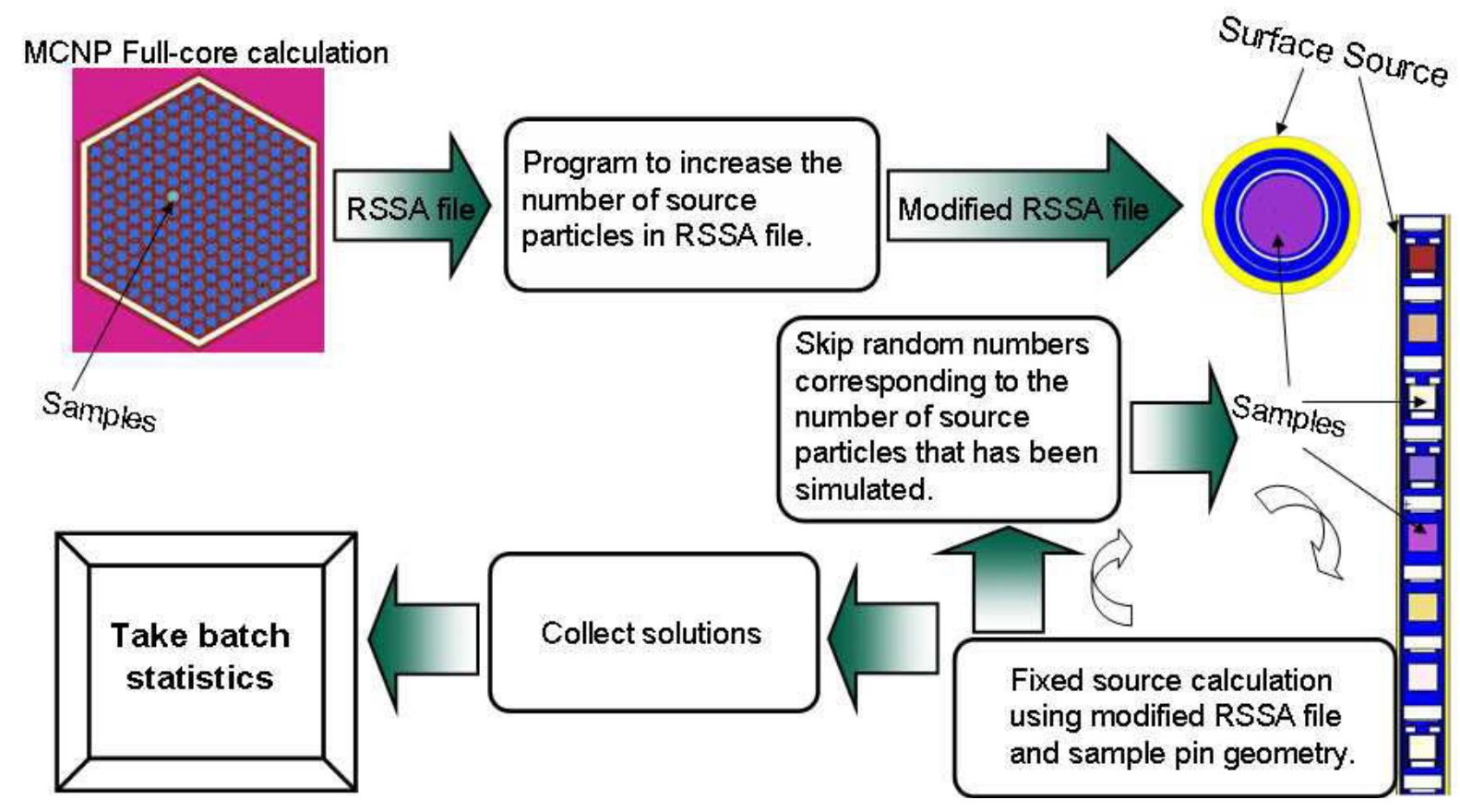

Figure 10: Procedure for calculating one-group cross sections by MCNP. 
Table XXI: Calculated one-group cross sections for Sample 1 (U235)

\begin{tabular}{|c|c|c|c|c|c|c|c|}
\hline $\begin{array}{l}\text { Reaction } \\
\text { (MT) }^{a}\end{array}$ & Isotope & XS [barn] & $\begin{array}{c}\text { Relative } \\
\text { Error [\%] }\end{array}$ & Reaction & Isotope & XS [barn] & $\begin{array}{c}\text { Relative Error } \\
{[\%]}\end{array}$ \\
\hline 16 & U234 & $3.037840 \mathrm{E}-04$ & 5.405779 & 16 & Nd143 & $1.060680 \mathrm{E}-03$ & 4.712392 \\
\hline 18 & U234 & $3.515110 \mathrm{E}-01$ & 0.340001 & 103 & Nd143 & $1.397710 \mathrm{E}-06$ & 9.41343 \\
\hline 102 & U235 & $5.200940 \mathrm{E}-01$ & 0.28465 & 102 & $\mathrm{Nd} 144$ & $6.744250 \mathrm{E}-02$ & 1.061523 \\
\hline 16 & U235 & $1.615260 \mathrm{E}-03$ & 2.973529 & 16 & Nd144 & $5.659250 \mathrm{E}-04$ & 7.274614 \\
\hline 18 & U235 & $1.843810 \mathrm{E}+00$ & 0.231388 & 103 & Nd144 & $5.070580 \mathrm{E}-07$ & 21.592868 \\
\hline 102 & U236 & $4.178900 \mathrm{E}-01$ & 0.5135 & 102 & Nd145 & $4.136860 \mathrm{E}-01$ & 1.015527 \\
\hline 16 & U236 & $9.402970 \mathrm{E}-04$ & 4.394599 & 16 & Nd145 & $1.780370 \mathrm{E}-03$ & 4.104082 \\
\hline 17 & U236 & $5.890100 \mathrm{E}-06$ & 38.603775 & 107 & Nd145 & $2.559820 \mathrm{E}-05$ & 0.291464 \\
\hline 18 & U236 & $1.152540 \mathrm{E}-01$ & 0.455458 & 103 & Nd145 & $4.080940 \mathrm{E}-07$ & 17.544697 \\
\hline 102 & U238 & $2.748800 \mathrm{E}-01$ & 0.486127 & 102 & Nd146 & $8.008490 \mathrm{E}-02$ & 0.890986 \\
\hline 16 & $\mathrm{~Np} 237$ & $4.541470 \mathrm{E}-04$ & 4.254421 & 16 & Nd148 & $9.196060 \mathrm{E}-04$ & 5.955908 \\
\hline 17 & $\mathrm{~Np} 237$ & $5.465450 \mathrm{E}-07$ & 39.542921 & 107 & Nd148 & $1.393440 \mathrm{E}-07$ & 15.38162 \\
\hline 18 & $\mathrm{~Np} 237$ & $3.748080 \mathrm{E}-01$ & 0.352052 & 103 & Nd148 & $5.878040 \mathrm{E}-08$ & 35.712273 \\
\hline 102 & $\mathrm{Pu} 239$ & $4.613240 \mathrm{E}-01$ & 0.501309 & 102 & Nd150 & $1.307540 \mathrm{E}-01$ & 1.702744 \\
\hline 16 & $\mathrm{Pu} 239$ & $4.858250 \mathrm{E}-04$ & 3.357739 & 16 & Nd150 & $8.367720 \mathrm{E}-04$ & 6.161138 \\
\hline 17 & $\mathrm{Pu} 239$ & $8.652000 \mathrm{E}-07$ & 41.354102 & 107 & Nd150 & $3.463640 \mathrm{E}-08$ & 29.090079 \\
\hline 18 & $\mathrm{Pu} 239$ & $1.783370 \mathrm{E}+00$ & 0.241661 & 103 & Nd150 & $2.584370 \mathrm{E}-08$ & 38.230922 \\
\hline
\end{tabular}

Table XXII: Calculated one-group cross sections for Sample 9 (Pu239)

\begin{tabular}{|c|c|c|c|c|c|c|c|}
\hline $\begin{array}{l}\text { Reaction } \\
\text { (MT) }\end{array}$ & Isotope & XS [barn] & $\begin{array}{c}\text { Relative } \\
\text { Error [\%] }\end{array}$ & Reaction & Isotope & XS [barn] & $\begin{array}{c}\text { Relative Error } \\
{[\%]}\end{array}$ \\
\hline 16 & U235 & $1.309630 \mathrm{E}-03$ & 3.018402 & 18 & $\mathrm{Pu} 242$ & $2.895290 \mathrm{E}-01$ & 0.34421 \\
\hline 18 & U235 & $1.854340 \mathrm{E}+00$ & 0.218769 & 16 & Nd143 & $7.810170 \mathrm{E}-04$ & 5.097732 \\
\hline 102 & U238 & $2.788660 \mathrm{E}-01$ & 0.539614 & 107 & $\mathrm{Nd} 143$ & $1.373350 \mathrm{E}-04$ & 0.467075 \\
\hline 16 & U238 & $1.607300 \mathrm{E}-03$ & 4.038454 & 103 & Nd143 & $9.754650 \mathrm{E}-07$ & 5.519241 \\
\hline 102 & Np237 & $1.530440 \mathrm{E}+00$ & 0.255034 & 107 & Nd144 & $4.775180 \mathrm{E}-06$ & 1.017322 \\
\hline 16 & Np237 & $3.327800 \mathrm{E}-04$ & 4.672836 & 103 & Nd144 & $2.373220 \mathrm{E}-07$ & 10.316824 \\
\hline 17 & Np237 & $1.248490 \mathrm{E}-09$ & 44.918811 & 102 & $\mathrm{Nd} 145$ & $4.119220 \mathrm{E}-01$ & 0.827633 \\
\hline 18 & Np237 & $3.698680 \mathrm{E}-01$ & 0.328834 & 16 & Nd145 & $1.318890 \mathrm{E}-03$ & 4.358531 \\
\hline 102 & $\mathrm{Pu} 239$ & $4.600080 \mathrm{E}-01$ & 0.38868 & 107 & Nd145 & $2.533040 \mathrm{E}-05$ & 0.254283 \\
\hline 16 & $\mathrm{Pu} 240$ & $2.424250 \mathrm{E}-04$ & 5.49969 & 103 & Nd146 & $3.364360 \mathrm{E}-08$ & 15.324273 \\
\hline 17 & $\mathrm{Pu} 240$ & $2.043910 \mathrm{E}-08$ & 45.354636 & 102 & Nd148 & $1.187430 \mathrm{E}-01$ & 1.533633 \\
\hline 18 & $\mathrm{Pu} 240$ & $4.119750 \mathrm{E}-01$ & 0.308059 & 16 & Nd148 & $6.518660 \mathrm{E}-04$ & 6.734455 \\
\hline 102 & $\mathrm{Pu} 241$ & $4.161960 \mathrm{E}-01$ & 0.268581 & 107 & Nd148 & $8.413170 \mathrm{E}-08$ & 5.653535 \\
\hline 16 & $\mathrm{Pu} 241$ & $2.358720 \mathrm{E}-03$ & 2.532586 & 103 & Nd148 & $7.999490 \mathrm{E}-09$ & 17.714538 \\
\hline 17 & $\mathrm{Pu} 241$ & $7.121060 \mathrm{E}-07$ & 38.645888 & 102 & Nd150 & $1.322880 \mathrm{E}-01$ & 1.610215 \\
\hline 18 & $\mathrm{Pu} 241$ & $2.442180 \mathrm{E}+00$ & 0.218104 & 16 & $\mathrm{Nd} 150$ & $5.997310 \mathrm{E}-04$ & 6.953367 \\
\hline 102 & $\mathrm{Pu} 242$ & $4.086690 \mathrm{E}-01$ & 0.374421 & 107 & Nd150 & $9.991550 \mathrm{E}-09$ & 11.565467 \\
\hline 16 & $\mathrm{Pu} 242$ & $6.603680 \mathrm{E}-04$ & 4.598729 & 103 & Nd150 & $1.853950 \mathrm{E}-09$ & 22.743318 \\
\hline
\end{tabular}

\footnotetext{
${ }^{\mathrm{a}} \mathrm{MT}=16:(\mathrm{n}, 2 \mathrm{n}), \mathrm{MT}=17:(\mathrm{n}, 3 \mathrm{n}), \mathrm{MT}=18:(\mathrm{n}, \mathrm{f}), \mathrm{MT}=102:(\mathrm{n}, \gamma), \mathrm{MT}=103:(\mathrm{n}, \mathrm{p}), \mathrm{MT}=107:(\mathrm{n}, \alpha)$
} 
Table XXIII: Calculated one-group cross sections for Sample 12 (U238)

\begin{tabular}{|c|c|c|c|c|c|c|c|}
\hline $\begin{array}{c}\text { Reaction } \\
\text { (MT) }\end{array}$ & Isotope & XS [barn] & $\begin{array}{c}\text { Relative } \\
\text { Error [\%] }\end{array}$ & Reaction & Isotope & XS [barn] & $\begin{array}{c}\text { Relative Error } \\
{[\%]}\end{array}$ \\
\hline 102 & U235 & $5.277180 \mathrm{E}-01$ & 0.275358 & 17 & $\mathrm{Pu} 242$ & $3.843550 \mathrm{E}-07$ & 43.481297 \\
\hline 16 & U235 & $1.309630 \mathrm{E}-03$ & 3.018402 & 18 & $\mathrm{Pu} 242$ & $2.895290 \mathrm{E}-01$ & 0.34421 \\
\hline 18 & U235 & $1.854340 \mathrm{E}+00$ & 0.218769 & 16 & Nd143 & $7.810170 \mathrm{E}-04$ & 5.097732 \\
\hline 102 & U238 & $2.788660 \mathrm{E}-01$ & 0.539614 & 107 & Nd143 & $1.373350 \mathrm{E}-04$ & 0.467075 \\
\hline 16 & U238 & $1.607300 \mathrm{E}-03$ & 4.038454 & 103 & Nd143 & $9.754650 \mathrm{E}-07$ & 5.519241 \\
\hline 18 & $\mathrm{U} 238$ & $4.957540 \mathrm{E}-02$ & 0.533836 & 16 & $\mathrm{Nd} 144$ & $4.176980 \mathrm{E}-04$ & 8.055213 \\
\hline 102 & Np237 & $1.530440 \mathrm{E}+00$ & 0.255034 & 107 & Nd144 & $4.775180 \mathrm{E}-06$ & 1.017322 \\
\hline 16 & Np237 & $3.327800 \mathrm{E}-04$ & 4.672836 & 103 & Nd144 & $2.373220 \mathrm{E}-07$ & 10.316824 \\
\hline 17 & Np237 & $1.248490 \mathrm{E}-09$ & 44.918811 & 102 & Nd145 & $4.119220 \mathrm{E}-01$ & 0.827633 \\
\hline 18 & Np237 & $3.698680 \mathrm{E}-01$ & 0.328834 & 16 & $\mathrm{Nd} 145$ & $1.318890 \mathrm{E}-03$ & 4.358531 \\
\hline 102 & $\mathrm{Pu} 239$ & $4.600080 \mathrm{E}-01$ & 0.38868 & 107 & $\mathrm{Nd} 145$ & $2.533040 \mathrm{E}-05$ & 0.254283 \\
\hline 16 & $\mathrm{Pu} 240$ & $2.424250 \mathrm{E}-04$ & 5.49969 & 103 & Nd146 & $3.364360 \mathrm{E}-08$ & 15.324273 \\
\hline 17 & $\mathrm{Pu} 240$ & $2.043910 \mathrm{E}-08$ & 45.354636 & 102 & Nd148 & $1.187430 \mathrm{E}-01$ & 1.533633 \\
\hline 18 & $\mathrm{Pu} 240$ & $4.119750 \mathrm{E}-01$ & 0.308059 & 16 & Nd148 & $6.518660 \mathrm{E}-04$ & 6.734455 \\
\hline 102 & $\mathrm{Pu} 241$ & $4.161960 \mathrm{E}-01$ & 0.268581 & 107 & Nd148 & $8.413170 \mathrm{E}-08$ & 5.653535 \\
\hline 16 & $\mathrm{Pu} 241$ & $2.358720 \mathrm{E}-03$ & 2.532586 & 103 & Nd148 & $7.999490 \mathrm{E}-09$ & 17.714538 \\
\hline 17 & $\mathrm{Pu} 241$ & $7.121060 \mathrm{E}-07$ & 38.645888 & 102 & Nd150 & $1.322880 \mathrm{E}-01$ & 1.610215 \\
\hline 18 & $\mathrm{Pu} 241$ & $2.442180 \mathrm{E}+00$ & 0.218104 & 16 & Nd150 & $5.997310 \mathrm{E}-04$ & 6.953367 \\
\hline 102 & $\mathrm{Pu} 242$ & $4.086690 \mathrm{E}-01$ & 0.374421 & 107 & Nd150 & $9.991550 \mathrm{E}-09$ & 11.565467 \\
\hline 16 & $\mathrm{Pu} 242$ & $6.603680 \mathrm{E}-04$ & 4.598729 & 103 & $\mathrm{Nd} 150$ & $1.853950 \mathrm{E}-09$ & 22.743318 \\
\hline
\end{tabular}

Table XXIV: Calculated one-group cross sections for Sample 13 (Pu240)

\begin{tabular}{|c|c|c|c|c|c|c|c|}
\hline $\begin{array}{l}\text { Reaction } \\
\text { (MT) }\end{array}$ & Isotope & XS [barn] & $\begin{array}{c}\text { Relative } \\
\text { Error [\%] }\end{array}$ & Reaction & Isotope & XS [barn] & $\begin{array}{c}\text { Relative Error } \\
{[\%]}\end{array}$ \\
\hline 102 & $\mathrm{Pu} 238$ & $6.976630 \mathrm{E}-01$ & 0.362389 & 107 & $\mathrm{Nd} 143$ & $1.384180 \mathrm{E}-04$ & 0.473173 \\
\hline 16 & $\mathrm{Pu} 238$ & $5.935060 \mathrm{E}-04$ & 5.380859 & 103 & $\mathrm{Nd} 143$ & $1.429740 \mathrm{E}-06$ & 7.894064 \\
\hline 17 & $\mathrm{Pu} 238$ & $2.937740 \mathrm{E}-05$ & 25.009649 & 102 & $\mathrm{Nd} 144$ & $7.023810 \mathrm{E}-02$ & 1.316051 \\
\hline 18 & $\mathrm{Pu} 238$ & $1.155630 \mathrm{E}+00$ & 0.227027 & 16 & Nd144 & $5.513400 \mathrm{E}-04$ & 6.39402 \\
\hline 102 & $\mathrm{Pu} 239$ & $4.576890 \mathrm{E}-01$ & 0.407591 & 107 & Nd144 & $5.062760 \mathrm{E}-06$ & 1.216924 \\
\hline 16 & $\mathrm{Pu} 239$ & $4.369230 \mathrm{E}-04$ & 3.224929 & 103 & Nd144 & $5.967070 \mathrm{E}-07$ & 16.238455 \\
\hline 17 & $\mathrm{Pu} 239$ & $1.341780 \mathrm{E}-06$ & 28.588982 & 102 & $\mathrm{Nd} 145$ & $4.067260 \mathrm{E}-01$ & 0.858495 \\
\hline 18 & $\mathrm{Pu} 239$ & $1.781640 \mathrm{E}+00$ & 0.216085 & 16 & Nd145 & $1.627560 \mathrm{E}-03$ & 3.941579 \\
\hline 102 & $\mathrm{Pu} 240$ & $4.784400 \mathrm{E}-01$ & 0.500252 & 107 & $\mathrm{Nd} 145$ & $2.554790 \mathrm{E}-05$ & 0.26624 \\
\hline 16 & $\mathrm{Pu} 240$ & $3.199300 \mathrm{E}-04$ & 4.633435 & 103 & $\mathrm{Nd} 145$ & $4.571300 \mathrm{E}-07$ & 13.747319 \\
\hline 17 & $\mathrm{Pu} 240$ & $1.832170 \mathrm{E}-06$ & 25.359156 & 102 & $\mathrm{Nd146}$ & $7.985380 \mathrm{E}-02$ & 0.756263 \\
\hline 18 & $\mathrm{Pu} 240$ & $4.168140 \mathrm{E}-01$ & 0.304106 & 16 & $\mathrm{Nd} 146$ & $7.273530 \mathrm{E}-04$ & 5.936211 \\
\hline 102 & $\mathrm{Pu} 241$ & $4.176530 \mathrm{E}-01$ & 0.365439 & 107 & Nd146 & $8.347250 \mathrm{E}-07$ & 4.544443 \\
\hline 16 & $\mathrm{Pu} 241$ & $2.489380 \mathrm{E}-03$ & 2.396945 & 103 & $\mathrm{Nd} 146$ & $1.909500 \mathrm{E}-07$ & 21.552215 \\
\hline 17 & $\mathrm{Pu} 241$ & $5.433490 \mathrm{E}-06$ & 22.437151 & 102 & Nd148 & $1.234790 \mathrm{E}-01$ & 1.541685 \\
\hline 18 & $\mathrm{Pu} 241$ & $2.437120 \mathrm{E}+00$ & 0.218769 & 16 & Nd148 & $8.961500 \mathrm{E}-04$ & 5.385374 \\
\hline 102 & $\mathrm{Pu} 242$ & $4.118030 \mathrm{E}-01$ & 0.434057 & 107 & Nd148 & $1.557470 \mathrm{E}-07$ & 12.126587 \\
\hline 16 & $\mathrm{Pu} 242$ & $8.176650 \mathrm{E}-04$ & 4.123042 & 103 & Nd148 & $7.992250 \mathrm{E}-08$ & 22.947718 \\
\hline 17 & $\mathrm{Pu} 242$ & $1.451630 \mathrm{E}-05$ & 22.949458 & 102 & $\mathrm{Nd} 150$ & $1.307370 \mathrm{E}-01$ & 1.43651 \\
\hline 18 & $\mathrm{Pu} 242$ & $2.942560 \mathrm{E}-01$ & 0.342594 & 16 & Nd150 & $8.137710 \mathrm{E}-04$ & 5.533831 \\
\hline 102 & $\mathrm{Nd} 143$ & $2.571690 \mathrm{E}-01$ & 1.510225 & 107 & Nd150 & $4.531070 \mathrm{E}-08$ & 20.221757 \\
\hline 16 & $\mathrm{Nd} 143$ & $9.772800 \mathrm{E}-04$ & 4.444862 & 103 & $\mathrm{Nd} 150$ & $3.866530 \mathrm{E}-08$ & 25.071854 \\
\hline
\end{tabular}


Table XXV: Calculated one-group cross sections for Sample 15 (Pu242)

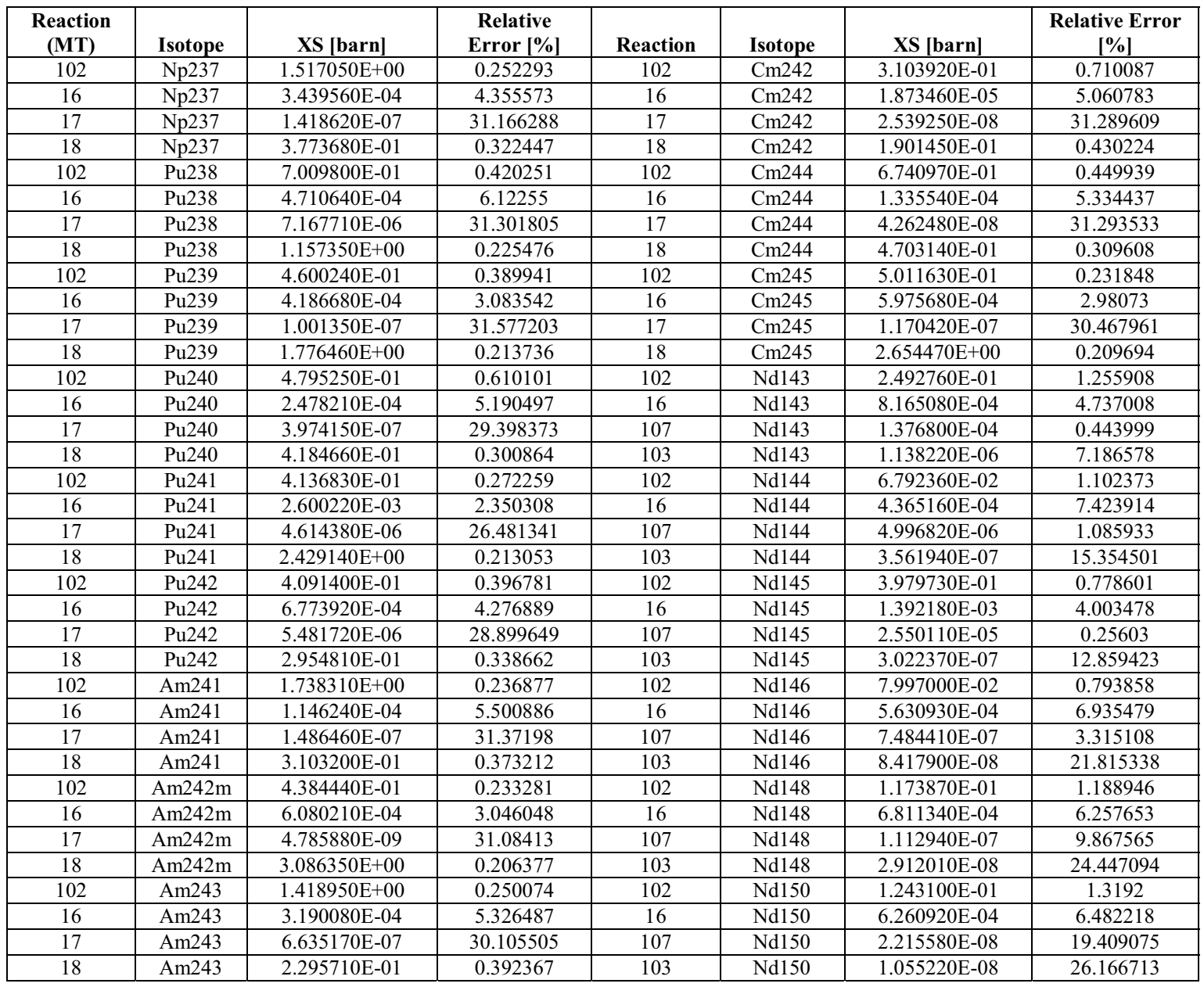

Table XXVI: Calculated one-group cross sections for Sample 36 (Pu241)

\begin{tabular}{|c|c|c|c|c|c|c|c|}
\hline $\begin{array}{l}\text { Reaction } \\
\text { (MT) }\end{array}$ & Isotope & XS [barn] & $\begin{array}{c}\text { Relative } \\
\text { Error }[\%]\end{array}$ & Reaction & Isotope & XS [barn] & $\begin{array}{c}\text { Relative Error } \\
{[\%]}\end{array}$ \\
\hline 16 & $\mathrm{Pu} 238$ & $6.308990 \mathrm{E}-04$ & 5.375226 & 16 & Nd144 & $5.651300 \mathrm{E}-04$ & 6.238304 \\
\hline 18 & $\mathrm{Pu} 238$ & $1.159250 \mathrm{E}+00$ & 0.229085 & 103 & Nd144 & $2.847780 \mathrm{E}-07$ & 9.942706 \\
\hline 102 & $\mathrm{Pu} 239$ & $4.651190 \mathrm{E}-01$ & 0.422382 & 102 & $\mathrm{Nd} 145$ & $4.104960 \mathrm{E}-01$ & 0.812978 \\
\hline 16 & $\mathrm{Pu} 239$ & $4.727810 \mathrm{E}-04$ & 3.11634 & 16 & $\mathrm{Nd} 145$ & $1.690620 \mathrm{E}-03$ & 3.849516 \\
\hline 102 & $\mathrm{Pu} 240$ & $4.775640 \mathrm{E}-01$ & 0.445268 & 102 & Nd146 & $8.113920 \mathrm{E}-02$ & 0.837365 \\
\hline 16 & $\mathrm{Pu} 240$ & $3.233130 \mathrm{E}-04$ & 4.652343 & 16 & $\mathrm{Nd} 146$ & $7.396350 \mathrm{E}-04$ & 5.888609 \\
\hline 17 & $\mathrm{Pu} 240$ & $6.769620 \mathrm{E}-08$ & 31.412545 & 107 & Nd146 & $7.675940 \mathrm{E}-07$ & 2.150585 \\
\hline 18 & $\mathrm{Pu} 240$ & $4.190620 \mathrm{E}-01$ & 0.304106 & 103 & Nd146 & $4.392080 \mathrm{E}-08$ & 17.856296 \\
\hline 102 & $\mathrm{Pu} 241$ & 4.179980E-01 & 0.291499 & 102 & Nd148 & $1.154950 \mathrm{E}-01$ & 1.275674 \\
\hline 16 & $\mathrm{Pu} 242$ & $8.598570 \mathrm{E}-04$ & 4.039659 & 16 & Nd150 & $8.215580 \mathrm{E}-04$ & 5.550308 \\
\hline 17 & $\mathrm{Pu} 242$ & $1.301690 \mathrm{E}-06$ & 31.659382 & 107 & Nd150 & $1.247380 \mathrm{E}-08$ & 13.451382 \\
\hline 18 & $\mathrm{Pu} 242$ & $2.966560 \mathrm{E}-01$ & 0.343394 & 103 & Nd150 & $3.090530 \mathrm{E}-09$ & 25.958101 \\
\hline 102 & $\mathrm{Nd} 143$ & $2.568710 \mathrm{E}-01$ & 1.374745 & 102 & Am241 & $1.749900 \mathrm{E}+00$ & 0.239709 \\
\hline 16 & $\mathrm{Nd} 143$ & $1.007090 \mathrm{E}-03$ & 4.305101 & 16 & Am241 & $1.479940 \mathrm{E}-04$ & 4.847007 \\
\hline
\end{tabular}


Report on INL Activities for Uncertainty Reduction Analysis of FY10

September 2010

\begin{tabular}{|c|c|c|c|c|c|c|c|}
\hline 107 & $\mathrm{Nd} 143$ & $1.406230 \mathrm{E}-04$ & 0.465366 & 17 & Am241 & $1.817260 \mathrm{E}-09$ & 42.329336 \\
\hline 103 & $\mathrm{Nd} 143$ & $1.185110 \mathrm{E}-06$ & 4.755913 & 18 & Am241 & $3.121010 \mathrm{E}-01$ & 0.377042 \\
\hline
\end{tabular}

Table XXVII: Calculated one-group cross sections for Sample 44 (Am241)

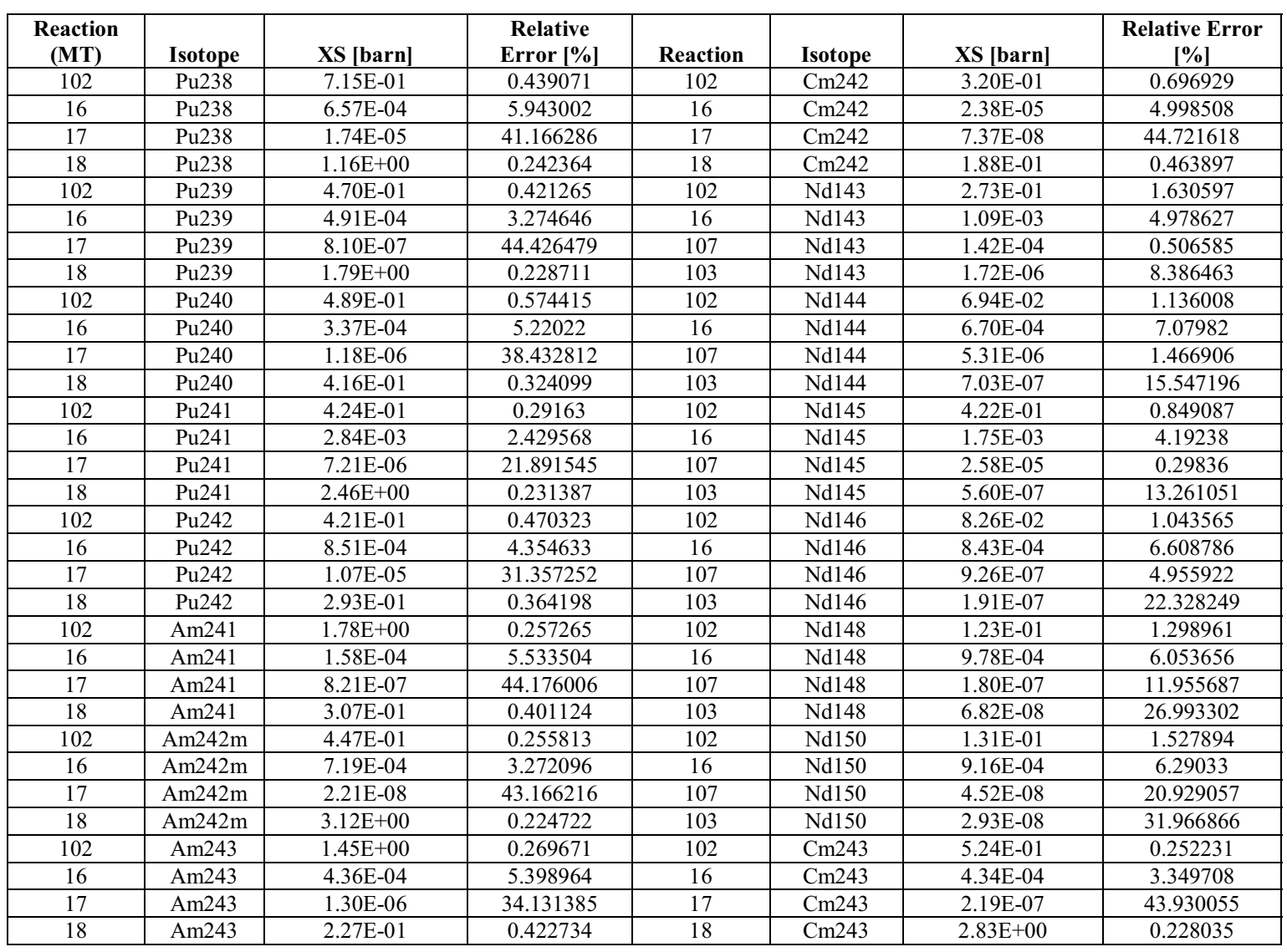

Table XXVIII: Calculated one-group cross sections for Sample 2 (Nd145)

\begin{tabular}{|c|c|c|c|c|c|c|c|}
\hline $\begin{array}{c}\text { Reaction } \\
(\mathbf{M T})\end{array}$ & Isotope & XS [barn] & $\begin{array}{c}\text { Relative } \\
\text { Error [\%] }\end{array}$ & Reaction & Isotope & $\begin{array}{c}\text { Relative Error } \\
{[\%]}\end{array}$ \\
\hline 102 & $\mathrm{Nd} 142$ & $2.81 \mathrm{E}-02$ & 1.027431 & 107 & $\mathrm{Nd} 145$ & $2.55 \mathrm{E}-05$ & 0.3107 \\
\hline 16 & $\mathrm{Nd} 142$ & $1.03 \mathrm{E}-04$ & 18.62023 & 103 & $\mathrm{Nd} 145$ & $4.26 \mathrm{E}-07$ & 13.991792 \\
\hline 107 & $\mathrm{Nd} 142$ & $2.52 \mathrm{E}-06$ & 2.2146 & 102 & $\mathrm{Nd} 146$ & $8.33 \mathrm{E}-02$ & 1.403236 \\
\hline 103 & $\mathrm{Nd} 142$ & $2.39 \mathrm{E}-06$ & 5.681982 & 16 & $\mathrm{Nd} 146$ & $7.66 \mathrm{E}-04$ & 7.042987 \\
\hline 102 & $\mathrm{Nd} 143$ & $2.49 \mathrm{E}-01$ & 1.21346 & 107 & $\mathrm{Nd} 146$ & $8.24 \mathrm{E}-07$ & 4.458915 \\
\hline 16 & $\mathrm{Nd} 143$ & $1.01 \mathrm{E}-03$ & 5.283313 & 103 & $\mathrm{Nd} 146$ & $1.34 \mathrm{E}-07$ & 22.96326 \\
\hline 107 & $\mathrm{Nd} 143$ & $1.38 \mathrm{E}-04$ & 0.568592 & 102 & $\mathrm{Nd} 148$ & $1.24 \mathrm{E}-01$ & 1.632772 \\
\hline 103 & $\mathrm{Nd} 143$ & $1.44 \mathrm{E}-06$ & 8.359074 & 16 & $\mathrm{Nd} 148$ & $9.21 \mathrm{E}-04$ & 6.449066 \\
\hline 102 & $\mathrm{Nd} 144$ & $6.73 \mathrm{E}-02$ & 1.268426 & 107 & $\mathrm{Nd} 148$ & $1.43 \mathrm{E}-07$ & 12.093025 \\
\hline 16 & $\mathrm{Nd} 144$ & $5.95 \mathrm{E}-04$ & 7.488501 & 103 & $\mathrm{Nd} 148$ & $4.97 \mathrm{E}-08$ & 25.582907 \\
\hline 107 & $\mathrm{Nd} 144$ & $5.09 \mathrm{E}-06$ & 1.411728 & 102 & $\mathrm{Nd} 150$ & $1.25 \mathrm{E}-01$ & 1.680664 \\
\hline 103 & $\mathrm{Nd} 144$ & $5.22 \mathrm{E}-07$ & 16.542815 & 16 & $\mathrm{Nd} 150$ & $8.48 \mathrm{E}-04$ & 6.631609 \\
\hline 102 & $\mathrm{Nd} 145$ & $3.98 \mathrm{E}-01$ & 0.781678 & 107 & $\mathrm{Nd} 150$ & $3.42 \mathrm{E}-08$ \\
\hline 16 & $\mathrm{Nd} 145$ & $1.66 \mathrm{E}-03$ & 4.655455 & 103 & $\mathrm{Nd} 150$ & $1.87 \mathrm{E}-08$ & 21.540802 \\
\hline
\end{tabular}

Table XXIX: Calculated one-group cross sections for Sample 3 (Pd105)

\begin{tabular}{|c|c|c|c|c|c|c|c|}
\hline $\begin{array}{c}\text { Reaction } \\
(\mathbf{M T})\end{array}$ & Isotope & XS [barn] & $\begin{array}{c}\text { Relative } \\
\text { Error [\%] }\end{array}$ & Reaction & Isotope & XS [barn] & $\begin{array}{c}\text { Relative Error } \\
{[\%]}\end{array}$ \\
\hline 102 & Pd104 & $2.19 \mathrm{E}-01$ & 1.019773 & 107 & Pd106 & $2.13 \mathrm{E}-06$ & 1.689971 \\
\hline 16 & Pd104 & $9.49 \mathrm{E}-05$ & 15.164891 & 103 & Pd106 & $6.22 \mathrm{E}-06$ & 5.498255 \\
\hline 107 & Pd104 & $2.00 \mathrm{E}-05$ & 0.968657 & 102 & Pd107 & $9.17 \mathrm{E}-01$ & 0.420714 \\
\hline 103 & Pd104 & $2.03 \mathrm{E}-05$ & 2.940298 & 16 & Pd107 & $1.54 \mathrm{E}-03$ & 5.12932 \\
\hline 102 & Pd105 & $8.25 \mathrm{E}-01$ & 0.433807 & 107 & Pd107 & $1.24 \mathrm{E}-06$ & 2.407368 \\
\hline
\end{tabular}




\begin{tabular}{|c|c|c|c|c|c|c|c|}
\hline 16 & Pd105 & $5.04 \mathrm{E}-04$ & 7.167139 & 103 & Pd107 & $1.96 \mathrm{E}-06$ & 6.959399 \\
\hline 107 & Pd105 & $6.99 \mathrm{E}-06$ & 2.011155 & 102 & Pd108 & $1.75 \mathrm{E}-01$ & 1.051305 \\
\hline 103 & Pd105 & $1.30 \mathrm{E}-05$ & 3.870212 & 16 & Pd108 & $2.30 \mathrm{E}-04$ & 12.478562 \\
\hline 102 & Pd106 & $1.93 \mathrm{E}-01$ & 1.147274 & 107 & Pd108 & $5.34 \mathrm{E}-07$ & 1.517169 \\
\hline 16 & Pd106 & $1.61 \mathrm{E}-04$ & 13.786093 & 103 & Pd108 & $1.14 \mathrm{E}-06$ & 9.465782 \\
\hline
\end{tabular}

Table XXX: Calculated one-group cross sections for Sample 4 (Cs133)

\begin{tabular}{|c|c|c|c|c|c|c|c|}
\hline $\begin{array}{c}\text { Reaction } \\
(\mathbf{M T})\end{array}$ & Isotope & XS [barn] & $\begin{array}{c}\text { Relative } \\
\text { Error [\%] }\end{array}$ & Reaction & Isotope & $\begin{array}{c}\text { Relative Error } \\
\text { [\%] }\end{array}$ \\
\hline 102 & Cs133 & $4.07 \mathrm{E}-01$ & 0.721867 & 107 & Cs135 & $1.19 \mathrm{E}-07$ & 14.444849 \\
\hline 16 & Cs133 & $1.86 \mathrm{E}-04$ & 14.29447 & 103 & Cs135 & $3.38 \mathrm{E}-07$ & 11.73155 \\
\hline 107 & Cs133 & $3.95 \mathrm{E}-07$ & 6.235385 & 102 & Cs136 & $1.72 \mathrm{E}-01$ & 0.945671 \\
\hline 103 & Cs133 & $3.07 \mathrm{E}-06$ & 5.614233 & 16 & Cs136 & $1.41 \mathrm{E}-03$ & 5.212342 \\
\hline 102 & Cs134 & $9.77 \mathrm{E}-01$ & 0.480507 & 107 & Cs136 & $1.08 \mathrm{E}-07$ & 12.979976 \\
\hline 16 & Cs134 & $1.24 \mathrm{E}-03$ & 5.402855 & 103 & Cs136 & $2.77 \mathrm{E}-07$ & 10.638784 \\
\hline 107 & Cs134 & $2.84 \mathrm{E}-07$ & 8.740878 & 102 & Cs137 & $1.50 \mathrm{E}-02$ & 0.447905 \\
\hline 103 & Cs134 & $9.36 \mathrm{E}-07$ & 6.588188 & 16 & Cs 137 & $4.82 \mathrm{E}-04$ & 8.890638 \\
\hline 102 & Cs135 & $1.97 \mathrm{E}-01$ & 1.965083 & 107 & Cs137 & $5.60 \mathrm{E}-08$ & 17.581152 \\
\hline 16 & Cs135 & $3.25 \mathrm{E}-04$ & 11.303191 & 103 & Cs137 & $7.76 \mathrm{E}-08$ & 21.913167 \\
\hline
\end{tabular}

Table XXXI: Calculated one-group cross sections for Sample 5 (Ru101)

\begin{tabular}{|c|c|c|c|c|c|c|c|}
\hline $\begin{array}{c}\text { Reaction } \\
(\mathbf{M T})\end{array}$ & Isotope & XS [barn] & $\begin{array}{c}\text { Relative } \\
\text { Error [\%] }\end{array}$ & Reaction & Isotope & $\begin{array}{c}\text { Relative Error } \\
\text { [\%] }\end{array}$ \\
\hline 102 & Ru99 & $5.14 \mathrm{E}-01$ & 0.613225 & 102 & Ru102 & $1.46 \mathrm{E}-01$ & 0.782423 \\
\hline 16 & Ru99 & $3.61 \mathrm{E}-04$ & 8.584078 & 16 & Ru102 & $7.66 \mathrm{E}-05$ & 16.121766 \\
\hline 107 & Ru99 & $1.87 \mathrm{E}-04$ & 0.483737 & 107 & Ru102 & $2.52 \mathrm{E}-06$ & 1.865327 \\
\hline 103 & Ru99 & $4.21 \mathrm{E}-05$ & 1.767726 & 103 & Ru102 & $2.02 \mathrm{E}-07$ & 13.568625 \\
\hline 102 & Ru101 & $6.53 \mathrm{E}-01$ & 0.434622 & 102 & Ru104 & $1.40 \mathrm{E}-01$ & 1.162442 \\
\hline 16 & Ru101 & $4.51 \mathrm{E}-04$ & 6.961693 & 16 & Ru104 & $1.39 \mathrm{E}-04$ & 13.859536 \\
\hline 107 & $\mathrm{Ru} 101$ & $3.11 \mathrm{E}-06$ & 2.072345 & 107 & Ru104 & $8.13 \mathrm{E}-08$ & 12.422718 \\
\hline 103 & $\mathrm{Ru} 101$ & $2.34 \mathrm{E}-06$ & 6.530199 & 103 & Ru104 & $1.41 \mathrm{E}-07$ & 16.977216 \\
\hline
\end{tabular}

Table XXXII: Calculated one-group cross sections for Sample 6 (Mo95)

\begin{tabular}{|c|c|c|c|c|c|c|c|}
\hline $\begin{array}{c}\text { Reaction } \\
(\mathbf{M T})\end{array}$ & Isotope & XS [barn] & $\begin{array}{c}\text { Relative } \\
\text { Error [\%] }\end{array}$ & Reaction & Isotope & $\begin{array}{c}\text { Relative Error } \\
{[\%]}\end{array}$ \\
\hline 102 & Mo92 & $4.94 \mathrm{E}-02$ & 1.157715 & 107 & Mo96 & $9.95 \mathrm{E}-06$ & 2.335464 \\
\hline 16 & Mo92 & $4.09 \mathrm{E}-07$ & 50.000259 & 103 & Mo96 & $2.80 \mathrm{E}-06$ & 6.624573 \\
\hline 107 & Mo92 & $1.70 \mathrm{E}-05$ & 2.50946 & 102 & Mo97 & $2.98 \mathrm{E}-01$ & 0.754448 \\
\hline 103 & Mo92 & $1.28 \mathrm{E}-03$ & 1.426761 & 16 & Mo97 & $5.34 \mathrm{E}-04$ & 6.395697 \\
\hline 102 & Mo94 & $8.64 \mathrm{E}-02$ & 1.185902 & 107 & Mo97 & $1.21 \mathrm{E}-05$ & 1.100379 \\
\hline 16 & Mo94 & $5.88 \mathrm{E}-05$ & 17.924637 & 103 & Mo97 & $1.73 \mathrm{E}-06$ & 6.406667 \\
\hline 107 & Mo94 & $1.13 \mathrm{E}-04$ & 1.164978 & 102 & Mo98 & $1.01 \mathrm{E}-01$ & 2.340548 \\
\hline 103 & Mo94 & $3.76 \mathrm{E}-05$ & 2.917465 & 16 & Mo98 & $1.97 \mathrm{E}-04$ & 11.2447 \\
\hline 102 & Mo95 & $2.86 \mathrm{E}-01$ & 0.696335 & 107 & Mo98 & $1.02 \mathrm{E}-06$ & 4.453965 \\
\hline 16 & Mo95 & $2.98 \mathrm{E}-04$ & 8.387237 & 103 & Mo98 & $1.78 \mathrm{E}-07$ & 13.404273 \\
\hline 107 & Mo95 & $5.42 \mathrm{E}-05$ & 0.584334 & 102 & Mo100 & $8.37 \mathrm{E}-02$ & 2.54908 \\
\hline 103 & Mo95 & $6.19 \mathrm{E}-06$ & 4.243817 & 16 & Mo100 & $2.51 \mathrm{E}-04$ & 10.901121 \\
\hline 102 & Mo96 & $7.50 \mathrm{E}-02$ & 1.60566 & 107 & Mo100 & $1.73 \mathrm{E}-07$ & 9.722251 \\
\hline 16 & Mo96 & $1.16 \mathrm{E}-04$ & 14.01882 & 103 & Mo100 & $2.75 \mathrm{E}-08$ & 20.233978 \\
\hline
\end{tabular}

Table XXXIII: Calculated one-group cross sections for Sample 17 (Sm149)

\begin{tabular}{|c|c|c|c|c|c|c|c|}
\hline $\begin{array}{c}\text { Reaction } \\
\text { (MT) }\end{array}$ & Isotope & XS [barn] & $\begin{array}{c}\text { Relative } \\
\text { Error [\%] }\end{array}$ & Reaction & Isotope & XS [barn] & $\begin{array}{c}\text { Relative Error } \\
{[\%]}\end{array}$ \\
\hline 102 & Sm144 & $7.64 \mathrm{E}-02$ & 0.793889 & 102 & Sm149 & $1.79 \mathrm{E}+00$ & 0.442685 \\
\hline 16 & Sm144 & $3.05 \mathrm{E}-05$ & 24.040339 & 16 & Sm149 & $1.24 \mathrm{E}-03$ & 4.683788 \\
\hline 107 & Sm144 & $1.70 \mathrm{E}-05$ & 0.850902 & 107 & Sm149 & $1.78 \mathrm{E}-05$ & 0.561266 \\
\hline 103 & Sm144 & $1.69 \mathrm{E}-05$ & 1.951226 & 103 & Sm149 & $4.05 \mathrm{E}-07$ & 9.543592 \\
\hline 102 & Sm147 & $9.64 \mathrm{E}-01$ & 0.6485 & 102 & Sm150 & $3.90 \mathrm{E}-01$ & 0.938065 \\
\hline
\end{tabular}




\begin{tabular}{|c|c|c|c|c|c|c|c|}
\hline 16 & Sm147 & $6.76 \mathrm{E}-04$ & 5.981097 & 16 & Sm150 & $3.84 \mathrm{E}-04$ & 8.614657 \\
\hline 107 & Sm147 & $6.19 \mathrm{E}-05$ & 0.415246 & 107 & Sm150 & $4.97 \mathrm{E}-07$ & 3.769555 \\
\hline 103 & Sm147 & $1.56 \mathrm{E}-06$ & 5.824855 & 103 & Sm150 & $1.15 \mathrm{E}-07$ & 18.11555 \\
\hline 102 & Sm148 & $2.36 \mathrm{E}-01$ & 1.132663 & 102 & Sm152 & $3.67 \mathrm{E}-01$ & 1.004419 \\
\hline 16 & Sm148 & $3.17 \mathrm{E}-04$ & 9.765922 & 16 & Sm152 & $3.37 \mathrm{E}-04$ & 9.702136 \\
\hline 107 & Sm148 & $6.80 \mathrm{E}-06$ & 0.81486 & 107 & Sm152 & $5.99 \mathrm{E}-08$ & 11.929181 \\
\hline 103 & Sm148 & $1.43 \mathrm{E}-07$ & 14.382811 & 103 & Sm152 & $6.65 \mathrm{E}-08$ & 18.533978 \\
\hline
\end{tabular}

\subsubsection{Depletion analysis with MCNP cross sections}

The "experimental" axial flux distribution has been provided by the French reports and has been derived by measurements of reaction rates at different places and times. Because of the differences between the experimental and calculated axial flux distributions, a comparison on the Neodymium production for the samples of U235 was performed using the two distributions. There were 6 samples of U235 located along the axis of the core. The results indicated that the experimental distribution provides a consistent (almost constant) set of C/E's, while the calculated one shows a drift in the bottom part. Based on this observation, it was decided that in the analysis we would use the experimental axial distribution. The likely reason for the observed discrepancy has to be attributed to the lack of information on the control rod movement during the cycles, and the actual flux calculations were performed with a fixed average control rod position.

Next step was to correctly normalize the isotope build up results to the actual values of the fluence (and hence eliminate the uncertainty in the irradiation history). To this latter purpose the neodymium production in the U235 samples has been calculated and compared with the correspondent experimental values. The corrective factor, by which the experimental fluxes are divided, has been subsequently derived. The normalization value used in the successive analysis is: 1.047.

Depletion calculations have been carried out using the NUTS [0] code in order to evaluate the isotope build up. The one group cross sections from the MCNP calculations and normalized fluxes were provided as inputs for the depletion calculations. , The information that can be gathered from the PROFIL post-irradiation analysis is related to the evaluation of the reaction rates (mainly capture and $(\mathrm{n}, 2 \mathrm{n})$ rates) for a given isotope. In particular, the analysis of the experiment is based on the relation existing between the burn-up dependent variations of the atom number densities and the microscopic cross-sections. For isotopes for which the descendant, obtained via neutron capture, is stable or has a long radioactive period, the most accurate experimental technique for obtaining information on the integral capture cross section is to determine the variation in composition that results from high-flux irradiation of a pure sample. Capture and $(\mathrm{n}, 2 \mathrm{n})$ reaction rates for an isotope of mass $\mathrm{A}$, which has received a total fluence of $\tau$, can be evaluated by the measurement of ratios of concentrations using Equations (1) and (2) respectively:

$$
\begin{aligned}
& \boldsymbol{\sigma}_{(c), A} \cdot \boldsymbol{\tau} \cdot f(\boldsymbol{\tau}) \cong \frac{\Delta N_{A+1}}{N_{A}}=\frac{N_{A+1}(\boldsymbol{\tau})}{N_{A}(\boldsymbol{\tau})}-\frac{N_{A+1}(0)}{N_{A}(0)} \\
& \boldsymbol{\sigma}_{(n, 2 n), A} \cdot \boldsymbol{\tau} \cdot f(\boldsymbol{\tau}) \cong \frac{\Delta N_{A-1}}{N_{A}}=\frac{N_{A-1}(\boldsymbol{\tau})}{N_{A}(\boldsymbol{\tau})}-\frac{N_{A-1}(0)}{N_{A}(0)}
\end{aligned}
$$

where $f(\tau)$ is a correcting factor which takes into account the physical phenomena different from capture (or $(\mathrm{n}, 2 \mathrm{n})$ reactions) that the considered isotope A can experience during the irradiation. Because 
of its definition $\mathrm{f}(\tau)$ is a measure of the fertile or fissile properties of a given isotope, being lower and higher than one for fertile and fissile isotopes respectively. It can be evaluated by a time dependent calculation, as follows:

$$
f(\tau)=\left[\frac{N_{A+1}^{(\tau)}}{N_{A}^{(\tau)}}-\frac{N_{A+1}^{(0)}}{N_{A}^{(0)}}\right] \times \frac{1}{\sigma_{C A} \cdot \tau_{c a l c .}}
$$

In Equation (3), $\sigma_{\mathrm{CA}}$ and $\tau_{\text {calc. }}$ represent the one-group capture cross section for the isotope $\mathrm{A}$ and the calculated fluence, respectively.

This approach works very well when we are considering a reaction rate that is dominant in the formation of the measured resulting isotope (i. e., capture cross section) but it will attribute the same $\mathrm{C} / \mathrm{E}$ also when the reaction rate is not dominant like in the case of an (n,2n) cross section. In order to avoid this problem a slightly different approach was adopted. We correct the experimental density variation by a calculated quantity that takes out the variation due to all the phenomena other than the reaction rate that we are considering:

$$
\boldsymbol{\sigma}_{(c), A} \cdot \boldsymbol{\tau} \cdot \cong \frac{{ }^{c o r r} \Delta N_{A+1}}{N_{A}}=\frac{{ }^{e x p} \Delta N_{A+1}(\boldsymbol{\tau})-\left({ }^{c a l c} \Delta N_{A+1}-N_{A}^{(0)} \boldsymbol{e}^{-\boldsymbol{\sigma \tau}}\right)}{N_{A}}
$$

where ${ }^{\exp } \boldsymbol{\Delta} N_{A+1}(\tau)$ is the experimental measured density variation, and ${ }^{\text {calc }} \boldsymbol{\Delta} N_{A+1}$ is the calculated one.

In the end Eq. 4 was used to derive an initial guess for the unknown experimental cross section and then this latter is computed by changing its value until the final measured experimental densities were matched. Using this new approach $\mathrm{C} / \mathrm{E}$ 's were calculated for the sample isotope build up. In Table XXXIV through Table XLVIII, we show, as an example, some selected C/E's on sample final densities and associated one group cross sections. The depletion decay chain used as branching ratio for the Am 241 capture $85 \%$ to $\mathrm{Am} 242$ (and $15 \%$ for $\mathrm{Am} 242 \mathrm{~m}$ ) and $83 \%$ to $\mathrm{Cm} 242$ and $17 \%$ to $\mathrm{Pu} 242$ for the $\beta$ decay of Am242. These values were found to produce the most consistent C/E's.

Table XXXIV C/E's: U235 samples

\begin{tabular}{|l|l|l|}
\hline Samples & $\mathrm{U} 236$ & $\mathrm{U} 235 \sigma_{\mathrm{c}}$ \\
\hline 1 & 0.944 & 0.942 \\
\hline 10 & 0.949 & 0.948 \\
\hline 19 & 0.944 & 0.943 \\
\hline 28 & 0.950 & 0.949 \\
\hline 37 & 0.953 & 0.952 \\
\hline 46 & 0.953 & 0.952 \\
\hline
\end{tabular}


Report on INL Activities for Uncertainty Reduction Analysis of FY10

Table XXXV C/E's: U238 samples

\begin{tabular}{|l|c|c|}
\hline Samples & Pu239 & U238 $\sigma_{c}$ \\
\hline 12 & 0.985 & 0.985 \\
\hline 23 & 0.962 & 0.962 \\
\hline 29 & 0.969 & 0.969 \\
\hline
\end{tabular}

Table XXXVI C/E's: Pu238 samples,

\begin{tabular}{|l|l|l|}
\hline Samples & Pu239 & Pu238 $\sigma_{\mathrm{c}}$ \\
\hline 7 & 1.113 & 1.299 \\
\hline 42 & 1.112 & 1.299 \\
\hline
\end{tabular}

Table XXXVII C/E's: Pu239 samples

\begin{tabular}{|l|l|l|l|c|}
\hline Samples & Pu238 & Pu240 & Pu239 $\sigma_{\mathrm{c}}$ & Pu239 $\sigma_{\mathrm{n}, 2 \mathrm{n}}$ \\
\hline 9 & 0.770 & 0.918 & 0.918 & 0.761 \\
\hline 20 & - & 0.901 & 0.901 & - \\
\hline 26 & 0.6736 & 0.899 & 0.899 & 0.728 \\
\hline
\end{tabular}

Table XXXVIII C/E's: Pu240 samples

\begin{tabular}{|l|l|l|l|l|}
\hline Samples & Pu239 & Pu241 & Pu240 $\sigma_{\mathrm{c}}$ & Pu241 $\sigma_{\mathrm{n}, 2 \mathrm{n}}$ \\
\hline 13 & 0.731 & 0.956 & 0.957 & 0.680 \\
\hline 22 & 0.828 & 0.960 & 0.960 & 0.878 \\
\hline 30 & - & 0.964 & 0.964 & - \\
\hline
\end{tabular}


Table IXXIX C/E's: Pu241 samples

\begin{tabular}{|l|l|l|}
\hline Samples & Pu242 & Pu241 $\sigma_{\mathrm{c}}$ \\
\hline 35 & 0.940 & 0.940 \\
\hline 18 & 0.970 & 0.956 \\
\hline 24 & 0.970 & 0.955 \\
\hline
\end{tabular}

Table XL C/E's: Pu242 sample

\begin{tabular}{|l|l|l|l|l|}
\hline Samples & Am243 & Cm244 & Pu242 $\sigma_{\mathrm{c}}$ & Am243 $\sigma_{\mathrm{c}}$ \\
\hline 15 & 1.058 & 0.826 & 1.058 & 0.768 \\
\hline 32 & 1.044 & 0.933 & 1.045 & 0.890 \\
\hline 40 & 1.078 & 0.925 & 1.079 & 0.852 \\
\hline
\end{tabular}

Table XLI C/E's: Am241 samples

\begin{tabular}{|l|c|c|c|c|c|c|}
\hline Samples & Pu238 & Pu242 & Am242 & $\sigma_{c}{ }^{\text {Am241 }}$ & ${ }^{\text {b) }}$ Am241 & $\sigma_{c}{ }^{\text {c) }}$ 241 \\
\hline 11 & 0.949 & 0.965 & 0.972 & 0.969 & 0.965 & 0.944 \\
\hline 44 & 0.949 & 0.988 & 1.001 & 1.001 & 0.988 & 0.945 \\
\hline
\end{tabular}

a) Calculated from Am242 build up. b) Calculated from Pu242 build up. c) Calculated from Pu238 build up

Table XLII C/E's: Mo95

\begin{tabular}{|l|l|l|}
\hline Samples & Mo96 & Mo95 $\sigma_{\mathrm{c}}$ \\
\hline 6 & 1.042 & 1.067 \\
\hline 33 & 0.997 & 0.996 \\
\hline
\end{tabular}


Report on INL Activities for Uncertainty Reduction Analysis of FY10

Table XLIII C/E's: Mo97 samples

\begin{tabular}{|l|l|l|}
\hline Samples & Mo98 & Mo97 $\sigma_{\mathrm{c}}$ \\
\hline 6 & 0.981 & 0.956 \\
\hline 33 & 1.008 & 0.980 \\
\hline
\end{tabular}

Table XLIV C/E's: Ru101 samples

\begin{tabular}{|l|l|l|}
\hline Samples & Ru102 & Ru101 $\sigma_{\mathrm{c}}$ \\
\hline 5 & 1.076 & 1.094 \\
\hline 27 & 1.093 & 1.112 \\
\hline 39 & 1.079 & 1.097 \\
\hline
\end{tabular}

Table XLV C/E's: Pd105 samples

\begin{tabular}{|l|l|l|}
\hline Samples & Pd106 & Pd105 $\sigma_{\mathrm{c}}$ \\
\hline 3 & 0.894 & 0.858 \\
\hline 34 & 0.878 & 0.845 \\
\hline
\end{tabular}

Table XLVI C/E’s: Cs133 samples

\begin{tabular}{|l|l|l|}
\hline Samples & Cs134 & Cs133 $\sigma_{\mathrm{c}}$ \\
\hline 4 & 0.868 & 0.868 \\
\hline 31 & 0.890 & 0.890 \\
\hline
\end{tabular}

Table XLVIIC/E's: Nd145 samples

\begin{tabular}{|l|l|l|}
\hline Samples & Nd146 & Nd145 $\sigma_{\mathrm{c}}$ \\
\hline 2 & 0.983 & 0.961 \\
\hline 41 & 0.974 & 0.948 \\
\hline
\end{tabular}


Table XLVIII C/E's: Sm149 samples

\begin{tabular}{|l|l|l|}
\hline Samples & Sm150 & Sm149 $\sigma_{\mathrm{c}}$ \\
\hline 17 & 0.922 & 0.925 \\
\hline 45 & 0.878 & 0.905 \\
\hline
\end{tabular}

\subsubsection{Depletion analysis with deterministic methodology}

In the following we report details of the deterministic calculation methodology used for the PROFIL1 analysis including multi-group cross section generation at the lattice cell level, full core burn-up, irradiation pin data extraction and condensation, and fine irradiation of isotope samples.

All neutronics calculations have been performed with modules of the ERANOS 2.1 code system. The cross sections with original data derived from the ENDF/B-VII evaluation have been processed over a 33group energy structure with the ECCO code. The spatial flux was obtained via the 3D VARIANT code based on the variational nodal transport method in $\mathrm{P}_{3}$ approximation and HEX-Z geometry. Fine irradiation and cooling of the isotope samples was performed with the MECCYCO fuel cycle code.

To prepare 33-group cross sections for the full core burn-up calculation, every material region in each PHENIX subassembly type was represented by an 2D ECCO unit cell. The active fuel regions of the three fuel subassembly types were modeled as heterogeneous cells with 217 fuel pins in a hexagonal lattice. Fuel pins, gap, clad, and wrapper tube were explicitly represented in accordance with geometrical data for PHENIX fuel subassemblies. The fuel pin spacer wire was smeared into the interstitial sodium coolant. All other material regions such as the axial and radial blankets, reflectors, and plenum were modeled as homogeneous regions with all number densities smeared into a hexagon. Number densities for all cells were derived from a R-Z PHENIX model provided by a French report [11]. Nuclide mass was preserved when converting the $\mathrm{R}-\mathrm{Z}$ region volumes and number densities into HEX-Z geometry.

The ECCO "reference route" presented in the ERANOS documentation was used to produce subassembly-averaged cross sections. For the heterogeneous fuel cells, collision probabilities are used for the flux solution and resonance self-shielding while the fundamental mode is assumed for homogenous cells. Heavy isotopes and common structural isotopes are treated at the fine group level (1968 energy group library) and cross sections are condensed to the 33-group structure. Fission product cross sections are originally derived from a 33 energy group library. Figure 11 shows the ECCO calculation steps used for the PROFIL-I analysis. 
Figure 11: ECCO Reference route steps for heterogeneous fuel unit cells.

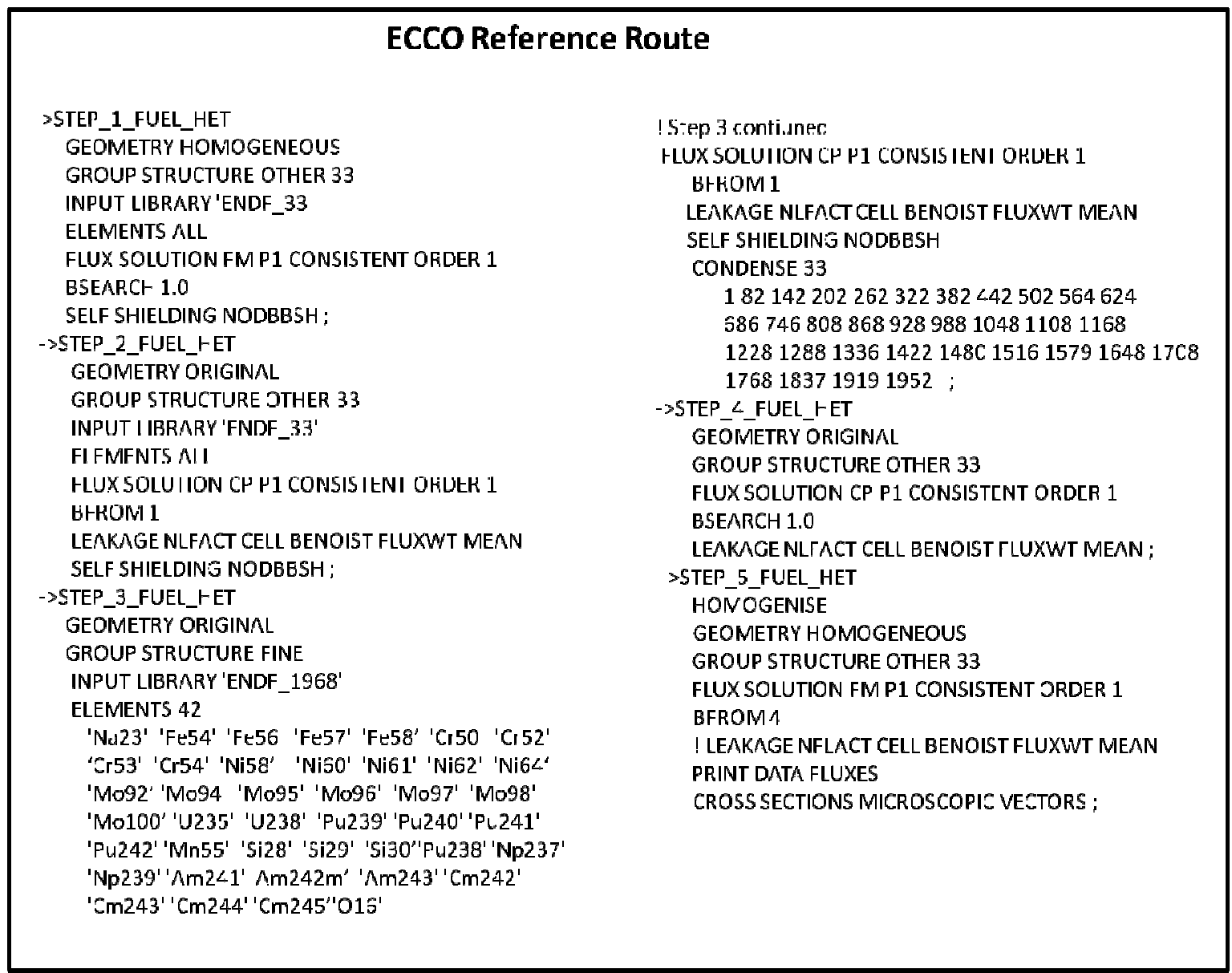

A modified ECCO calculation was performed for the center fuel subassembly which contains the irradiation pin in the third ring as shown in Figure 12. The ROTH x 6 surface method was used in the calculation route instead of the default collision probability option. The largest effect of the collision probability method was on the capture cross section of U238. For each actinide isotope sample type (U235, U238, Pu238, Pu239, Pu240, Pu241, Pu242, and Am241), a separate ECCO calculation was run with the mass of the corresponding oxide sample smeared in the interior volume of the sample capsule represented in the irradiation pin of the cell model. For the fission product samples, a single ECCO calculation was run with the capsule filled with equal fractions of each type of fission product sample. 
Figure 12: Central PHENIX Subassembly containing 217 fuel pins with a third ring pin replaced with the PROFIL-I irradiation pin modeled with the general lattice ECCO option.

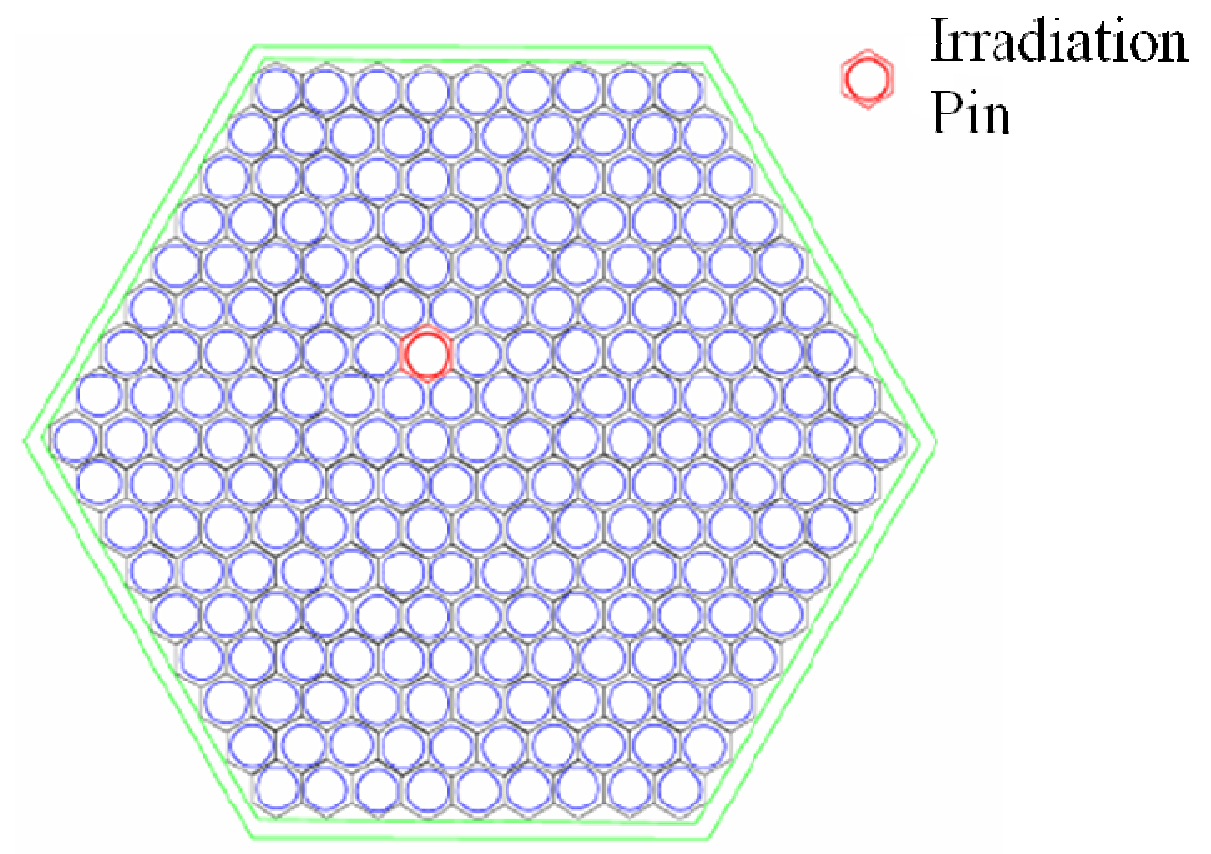

The first three irradiation cycles of PHENIX were modeled with a full core burn-up calculation with VARIANT providing the 33-group flux solution. The fuel regions were subdivided into 5 axial regions and the axial blankets were modeled as single zones. The actinide chains were explicitly tracked while Mo99 was used as the characteristic fission product. An average control rod position was used over all three cycles. At the beginning of each irradiation cycle, cross sections were recalculated in the burnable zones using the nuclide concentrations at the corresponding time. Figure 13 shows the calculated cycle dependent axial flux profile normalized to the "experimental" flux along the irradiation pin. Figure 14 shows the 33-group flux spectrum at the core midplane for Cycle 1. 
Figure 13: Burn-up dependent axial flux profiles along the irradiation pin. $Z=0$ corresponds to Sample 19 at the core midplane.

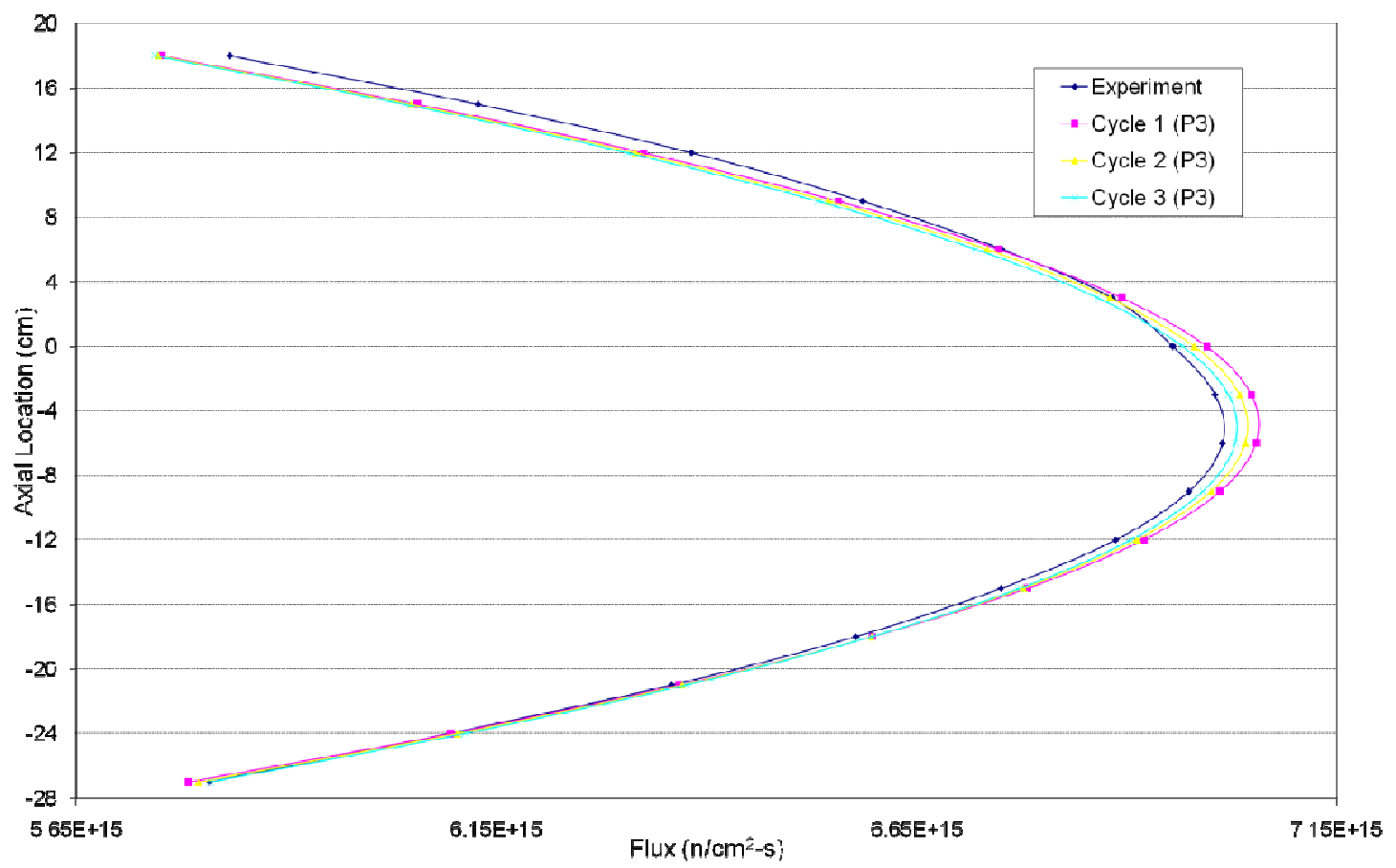

Figure 14: Cycle and axial position dependent flux spectra used as weighting function for one energy-group cross section generation for isotope samples.

\section{Normalized 33-group flux spectra at core midplane}

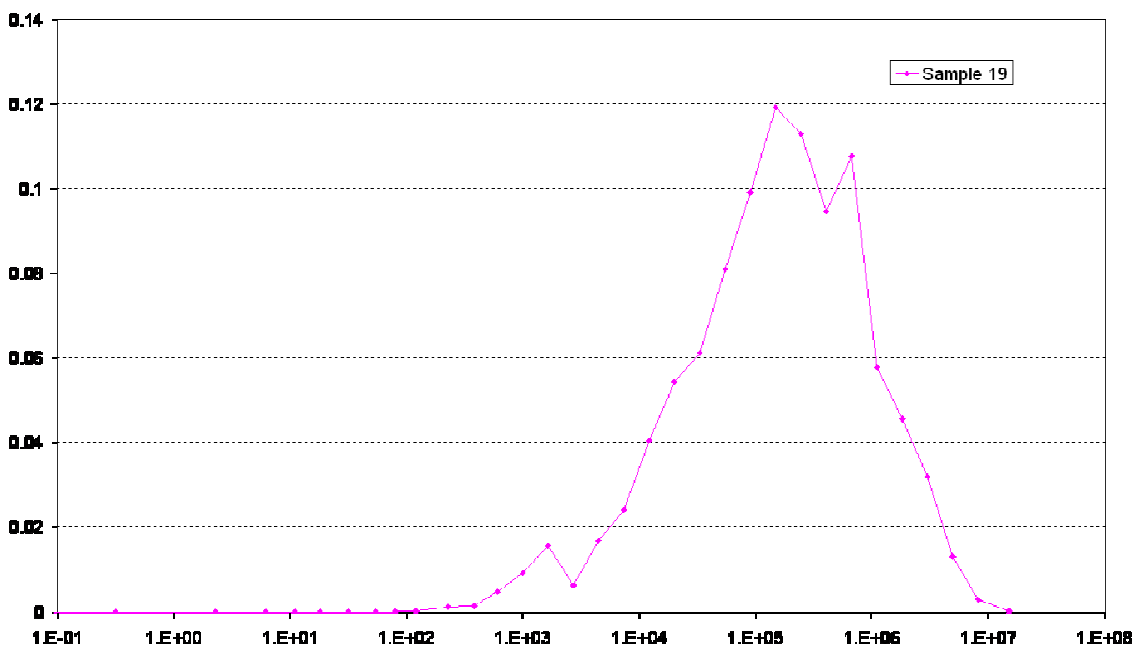

Average Group Energy (eV)

The ECCO model for the center subassembly provides 33-group cross sections for each sample type. The cycle dependent flux solutions provide 33-group flux spectra along the vertical axis of the irradiation pin. 
LU (ERANOS User's Language) procedures were developed to directly access and extract the (n,f), $(n, 2 n)$, and $(n, \gamma)$ 33-group cross sections for isotopes of the sample from the MICRO EDL (EDLs are data sets produced, stored, and accessed by ERANOS modules). Another LU procedure extracts the 33group flux spectra at each sample axial location and burn-up cycle from the ASVL EDL. Finally, the extracted flux spectra are used as weighting functions to collapse the cross sections to one energy-group to obtain cycle dependent, locally flux-weighted cross sections for every sample.

A detailed burn-up calculation for each sample was performed by the MECCYCO fuel cycle code. The one energy-group cross sections and initial isotope concentrations were provided as inputs to MECCYCO. The "experimental" flux profile and six-step burn-up scheme ( 3 irradiation steps and 3 cooling periods) that have been described in previous reports were utilized. Fission yields for the $\mathrm{Nd}$ isotopes were obtained from ENDF/B-VII evaluation through the JANIS 3.2 nuclear information software.

Nuclear decay data is provided in a library reference file that comes with the ERANOS cross section library files. Either a processing error by a MECCYCO/ERANOS function or erroneous data in the ENDF/B-VII reference file resulted in the decay constant for ground state Am242 to be set to zero indicating a stable isotope. The decay constant for ground state Am242 stored in the DECAY CHAIN EDL created by the MECCYCO/ERANOS function CREATION_CHAINE_EVOLUTION had to be manually changed to the correct decay constant value of $1.201878 \mathrm{E}-5 \mathrm{~s}^{-1}$. Some decay data such as branching ratios have to be provided by the user. The branching values for capture on Am 241 were set to $85 \% / 15 \%$ to ground state Am242 and metastable Am242, respectively. The branching values for the decay of ground state Am242 were set to $83 \% / 17 \%$ for beta- decay to $\mathrm{Cm} 242$ and electron capture to $\mathrm{Pu} 242$, respectively.

Six U235 samples were dispersed axially in the PROFIL-I irradiation pin. These samples serve as fluence monitors. The actual fluence can be derived by measuring the ratios of fission products with small absorption cross sections and well known fission yields (such as $\mathrm{Nd}$ ) to U235. The $\mathrm{C} / \mathrm{E}$ values for $\mathrm{Nd}$ concentrations in the U235 samples are shown in Table XLIX. For Nd143, Nd145, Nd146, and Nd148, the experimental flux was divided by a fluence normalization factor to obtain an average $\mathrm{C} / \mathrm{E}$ equal to 1 over all U235 samples (except for Sample 19). An average fluence normalization factor of 1.045 was obtained by averaging together the factors obtained for each individual $\mathrm{Nd}$ isotope.

\begin{tabular}{|c|c|c|c|c|c|c||c|}
\hline \multicolumn{7}{|c|}{ U235 Samples Before Fluence Normalization } \\
\hline & Sample 1 & Sample 10 & Sample 19 & Sample 28 & Sample 37 & Sample 46 & Average \\
\hline 'U234' & 1.012 & 1.013 & 1.014 & 1.014 & 1.009 & 1.007 & 1.011 \\
\hline 'U236' & 1.007 & 1.003 & 0.997 & 1.002 & 1.004 & 1.011 & 1.004 \\
\hline 'U238' & 1.006 & 1.001 & 0.994 & 1.013 & 1.015 & 0.990 & 1.003 \\
\hline 'Nd143' & 1.041 & 1.042 & 1.048 & 1.040 & 1.041 & 1.041 & 1.042 \\
\hline 'Nd144' & 1.071 & 1.068 & 1.210 & 1.102 & 1.075 & 1.064 & 1.098 \\
\hline 'Nd145' & 1.044 & 1.041 & 1.050 & 1.037 & 1.041 & 1.041 & 1.042 \\
\hline 'Nd146' & 1.061 & 1.056 & 1.066 & 1.050 & 1.045 & 1.040 & 1.053 \\
\hline 'Nd148' & 1.072 & 1.072 & 1.072 & 1.063 & 1.066 & 1.064 & 1.068 \\
\hline 'Nd150' & 1.094 & 1.092 & 1.097 & 1.087 & 1.087 & 1.086 & 1.090 \\
\hline
\end{tabular}


Table XLIX: C/E values for U235 samples before fluence normalization. Neodymium production from fission and Uranium isotope buildup

\begin{tabular}{|c|c|c|c|c|c|c||c|}
\hline \multicolumn{7}{|c|}{ U235 Samples After Fluence Normalization } \\
\hline & Sample 1 & Sample 10 & Sample 19 & Sample 28 & Sample 37 & Sample 46 & Average \\
\hline 'U234' & 1.005 & 1.006 & 1.006 & 1.006 & 1.001 & 1.001 & 1.004 \\
\hline 'U236' & 0.962 & 0.958 & 0.952 & 0.957 & 0.959 & 0.966 & 0.959 \\
\hline 'U238' & 0.999 & 0.993 & 0.985 & 1.004 & 1.006 & 0.982 & 0.995 \\
\hline 'Nd143' & 0.992 & 0.992 & 0.998 & 0.990 & 0.991 & 0.992 & 0.993 \\
\hline 'Nd144' & 1.019 & 1.016 & 1.150 & 1.048 & 1.022 & 1.013 & 1.045 \\
\hline 'Nd145' & 0.995 & 0.992 & 1.000 & 0.987 & 0.991 & 0.992 & 0.993 \\
\hline 'Nd146' & 1.010 & 1.004 & 1.013 & 0.998 & 0.993 & 0.990 & 1.001 \\
\hline 'Nd148' & 1.021 & 1.021 & 1.020 & 1.012 & 1.014 & 1.013 & 1.017 \\
\hline 'Nd150' & 1.042 & 1.040 & 1.044 & 1.035 & 1.035 & 1.035 & 1.038 \\
\hline
\end{tabular}

Table L: C/E values for $\mathrm{U} 235$ samples after fluence normalization.

Tables LI to LXIV show the C/E values for all isotope concentrations in the PROFIL-I samples. These values have been calculated using the six-step burn-up scheme adjusted by the fluence normalization factor.

Table LI: C/E U238 Samples.

\begin{tabular}{|c|c|c|c|}
\hline & Sample 12 & Sample 23 & Sample 29 \\
\hline 'U235' & 0.995 & 0.996 & 0.985 \\
\hline 'Pu239' & 0.970 & 0.967 & 0.964 \\
\hline 'Pu240' & 0.939 & 0.934 & 0.932 \\
\hline 'Pu241' & 0.961 & 1.000 & 0.989 \\
\hline
\end{tabular}

Table LII: C/E Pu238 Samples.

\begin{tabular}{|c|c|c|}
\hline & Sample 7 & Sample 42 \\
\hline 'Pu239' & 1.130 & 1.123 \\
\hline 'Pu240' & 1.024 & 1.021 \\
\hline 'Pu241' & 1.018 & 1.013 \\
\hline 'Pu242' & 0.997 & 0.982 \\
\hline
\end{tabular}


Table LIII: C/E Pu239 Samples.

\begin{tabular}{|c|c|c|c|}
\hline & Sample 9 & Sample 20 & Sample 26 \\
\hline 'Pu238' & 0.704 & 0.000 & 0.649 \\
\hline 'Pu240' & 0.928 & 0.918 & 0.923 \\
\hline 'Pu241' & 0.908 & 0.876 & 0.900 \\
\hline 'Pu242' & 1.273 & 0.000 & 1.431 \\
\hline
\end{tabular}

Table LIV: C/E Pu240 Samples.

\begin{tabular}{|c|c|c|c|}
\hline & Sample 13 & Sample 22 & Sample 30 \\
\hline 'Pu238' & 0.779 & 0.907 & 0.805 \\
\hline 'Pu239' & 0.704 & 0.786 & 0.362 \\
\hline 'Pu241' & 0.972 & 0.976 & 0.979 \\
\hline 'Pu242' & 1.004 & 0.962 & 0.993 \\
\hline
\end{tabular}

Table LV: C/E Pu241 Samples.

\begin{tabular}{|c|c|c|c|}
\hline & Sample 18 & Sample 24 & Sample 35 \\
\hline 'Pu238' & 0.502 & 0.501 & 1.950 \\
\hline 'Pu239' & 0.995 & 0.995 & 1.686 \\
\hline 'Pu240' & 1.000 & 0.999 & 1.102 \\
\hline 'Pu242' & 0.964 & 0.965 & 0.984 \\
\hline
\end{tabular}

Table LVI: C/E Pu242 Samples.

\begin{tabular}{|c|c|c|c|}
\hline & Sample 15 & Sample 32 & Sample 40 \\
\hline 'Pu238' & 0.744 & 0.871 & 0.944 \\
\hline 'Pu239' & 1.007 & 0.995 & 1.076 \\
\hline 'Pu240' & 1.004 & 1.000 & 1.004 \\
\hline 'Pu241' & 1.009 & 1.015 & 1.005 \\
\hline 'Am242m' & 3.055 & 2.479 & 3.042 \\
\hline 'Am243' & 1.071 & 1.045 & 1.071 \\
\hline 'Cm242' & 2.804 & 2.873 & 2.880 \\
\hline 'Cm244' & 0.839 & 0.934 & 0.920 \\
\hline
\end{tabular}


Table LVII: C/E Cs133 Samples.

\begin{tabular}{|c|c|c|}
\hline & Sample 4 & Sample 31 \\
\hline 'Cs134' & 0.908 & 0.899 \\
\hline 'Cs135' & 1.595 & 1.578 \\
\hline
\end{tabular}

Table LVIII: C/E Am241 Samples.

\begin{tabular}{|c|c|c|}
\hline & Sample 11 & Sample 44 \\
\hline 'Am242m' & 0.971 & 1.000 \\
\hline 'Am243' & 0.998 & 0.810 \\
\hline 'Pu238' & 0.971 & 0.968 \\
\hline 'Pu239' & 0.320 & 0.409 \\
\hline 'Pu240' & 0.087 & 0.170 \\
\hline 'Pu241' & 0.011 & 0.014 \\
\hline 'Pu242' & 0.945 & 0.966 \\
\hline 'Cm242' & 1.021 & 1.026 \\
\hline
\end{tabular}

Table LIX: C/E Nd145 Samples.

\begin{tabular}{|c|c|c|}
\hline & Sample 2 & Sample 41 \\
\hline 'Nd142' & 0.995 & 1.001 \\
\hline 'Nd143' & 1.000 & 1.000 \\
\hline 'Nd144' & 0.998 & 1.001 \\
\hline 'Nd146' & 1.009 & 1.011 \\
\hline 'Nd148' & 0.994 & 0.993 \\
\hline 'Nd150' & 1.017 & 1.012 \\
\hline
\end{tabular}

Table LX: C/E Pd105 Samples.

\begin{tabular}{|c|c|c|}
\hline & Sample 3 & Sample 34 \\
\hline 'Pd104' & 0.823 & 0.798 \\
\hline 'Pd106' & 0.884 & 0.876 \\
\hline 'Pd107' & 0.708 & 0.713 \\
\hline 'Pd108' & 0.708 & 0.734 \\
\hline
\end{tabular}


Table LXI: C/E Ru101 Samples.

\begin{tabular}{|c|c|c|c|}
\hline & Sample 5 & Sample 27 & Sample 39 \\
\hline 'Ru99' & 1.013 & 1.015 & 1.014 \\
\hline 'Ru102' & 1.102 & 1.102 & 1.103 \\
\hline 'Ru104' & 1.000 & 0.919 & 0.915 \\
\hline
\end{tabular}

Table LXII: C/E Sm149 Samples.

\begin{tabular}{|c|c|c|}
\hline & Sample 17 & Sample 45 \\
\hline 'Sm144' & 0.941 & 0.951 \\
\hline 'Sm147' & 0.994 & 0.997 \\
\hline 'Sm148' & 0.982 & 0.985 \\
\hline 'Sm150' & 0.918 & 0.924 \\
\hline 'Sm151' & 0.818 & 0.830 \\
\hline 'Sm152' & 0.995 & 0.997 \\
\hline
\end{tabular}

Table LXIII: C/E Mo95 Samples.

\begin{tabular}{|c|c|c|}
\hline & Sample 6 & Sample 33 \\
\hline 'Mo97' & 1.003 & 0.893 \\
\hline 'Mo92' & 0.991 & 0.796 \\
\hline 'Mo94' & 0.999 & 0.931 \\
\hline 'Mo96' & 1.027 & 1.004 \\
\hline 'Mo98' & 0.987 & 0.819 \\
\hline 'Mo100' & 0.965 & 0.751 \\
\hline
\end{tabular}

Table LXIV: C/E Mo97 Samples.

\begin{tabular}{|c|c|c|}
\hline & Sample 8 & Sample 43 \\
\hline 'Mo92' & 0.736 & 0.913 \\
\hline 'Mo94' & 0.806 & 0.941 \\
\hline 'Mo95' & 0.818 & 0.937 \\
\hline 'Mo96' & 0.923 & 0.971 \\
\hline 'Mo98' & 0.988 & 1.008 \\
\hline 'Mo100' & 0.797 & 0.914 \\
\hline
\end{tabular}




\subsubsection{Summary on PROFIL-1 analysis}

Table LXV summarizes the C/E with the ENDF/B-VII one group cross sections obtained using both stochastic and deterministic methodology. These results have been obtained by averaging the corresponding $\mathrm{C} / \mathrm{Es}$ over the different samples.

We will observe that there is a good consistency between the results obtained with the stochastic methodology and those obtained with the deterministic one as the discrepancies are inside the experimental uncertainties.

Large discrepancies of ENDF/B-VII data are noticeable for capture cross sections of Pu isotopes (Pu238, Pu239, and Pu242) and Am243. The (n,2n) cross sections of Pu239 and Pu240 appear to be largely underestimated. Regarding fission products, the capture cross sections of Ru101, Pd105, Cs133 , and Sm149 need to be improved.

\begin{tabular}{|c|c|c|c|}
\hline \multirow{2}{*}{$\sigma$} & \multicolumn{3}{|c|}{$\mathrm{C} / \mathrm{E}$} \\
\hline & MCNP & Deter. & Exp. Unc. \\
\hline$\sigma_{\text {capt }}$ U-235 & 0.948 & 0.958 & $1.7 \%$ \\
\hline$\sigma_{\text {capt }}$ U-238 & 0.972 & 0.967 & $2.3 \%$ \\
\hline$\sigma_{\text {capt }} \mathrm{Pu}-238$ & 1.299 & 1.348 & $4.0 \%$ \\
\hline$\sigma_{\text {capt }}$ Pu-239 & 0.906 & 0.922 & $3.0 \%$ \\
\hline$\sigma_{n, 2 n} P u-239$ & 0.745 & - & $15.0 \%$ \\
\hline$\sigma_{\text {capt }} \mathrm{Pu}-240$ & 0.964 & 0.976 & $2.2 \%$ \\
\hline$\sigma_{n, 2 n} P u-240$ & 0.779 & - & $15.0 \%$ \\
\hline$\sigma_{\text {capt }}$ Pu-241 & 0.950 & 0.956 & $4.1 \%$ \\
\hline$\sigma_{\text {capt }} \mathrm{Pu}-242$ & 1.061 & 1.062 & $3.5 \%$ \\
\hline$\sigma_{\text {capt }}$ Am-241 & 0.968 & - & $1.7 \%$ \\
\hline$\sigma_{\text {capt }} \mathrm{Am}-243$ & 0.834 & - & $5.0 \%$ \\
\hline$\sigma_{\text {capt }}$ Mo-95 & 1.032 & 1.025 & $3.8 \%$ \\
\hline$\sigma_{\text {capt }}$ Mo-97 & 0.968 & 0.993 & $4.4 \%$ \\
\hline$\sigma_{\text {capt }}$ Ru-101 & 1.101 & 1.124 & $3.6 \%$ \\
\hline$\sigma_{\text {capt }}$ Pd-105 & 0.852 & 0.834 & $4.0 \%$ \\
\hline$\sigma_{\text {capt }}$ Cs-133 & 0.878 & 0.905 & $4.7 \%$ \\
\hline$\sigma_{\text {capt }} \mathrm{Nd}-145$ & 0.955 & - & $3.8 \%$ \\
\hline$\sigma_{\text {capt }} \mathrm{Sm}-149$ & 0.915 & 0.924 & $3.1 \%$ \\
\hline
\end{tabular}

Table LXV. Sample averaged C/E for individual cross sections obtained with stochastic (MCNP) and deterministic methodology.

\subsection{PROFIL-2 and TRAPU Modeling}

Other experiments performed in the PHENIX reactor are PROFIL-2 and TRAPU [9]. In the last fiscal year, PROFIL-2 has been modeled using MCNP calculations (Figure 15). It has two irradiated fuel pins, in which each one has 42 irradiated samples. In order to calculate one-group cross sections for each sample, it is necessary to perform a similar technique to the one shown in Figure 10. In this fiscal year, we have modeled TRAPU for MCNP calculations (Figure 16). In the third assembly ring there are two 
subassemblies having total of 10 irradiated fuel pins (5 each). Unlike other two experiments, each irradiated fuel pin has only one sample which has the same size as that of ordinal fuel pin. The large volume of irradiated samples makes Monte Carlo calculations much simpler since the tallies of reactions can be easily done without performing the complicated procedure as shown in Figure 10. In the next fiscal year, we will perform depletion calculations and finalize the analysis of both PROFIL-2 and TRAPU.

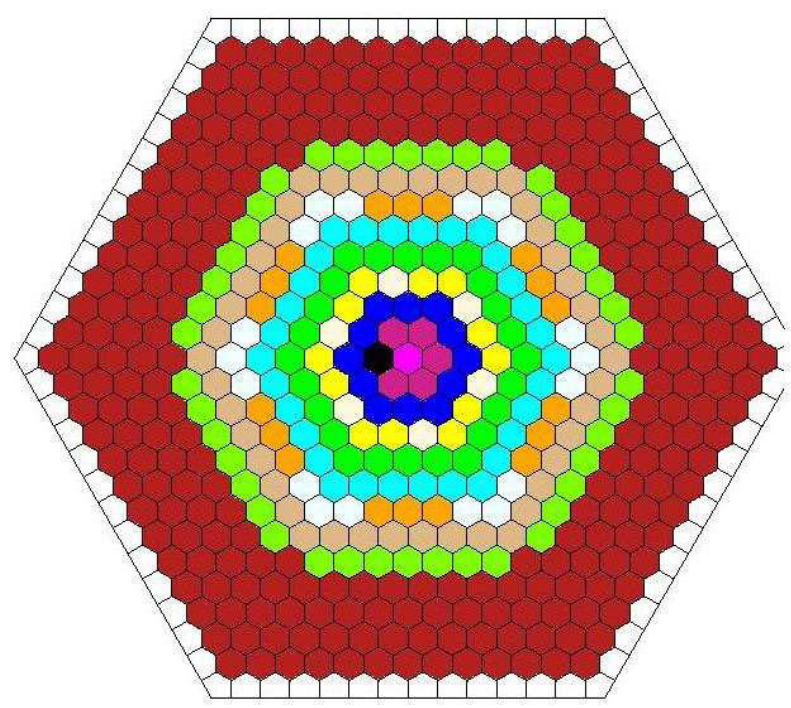

(a) Radial configuration during PROFIL-2 experiment

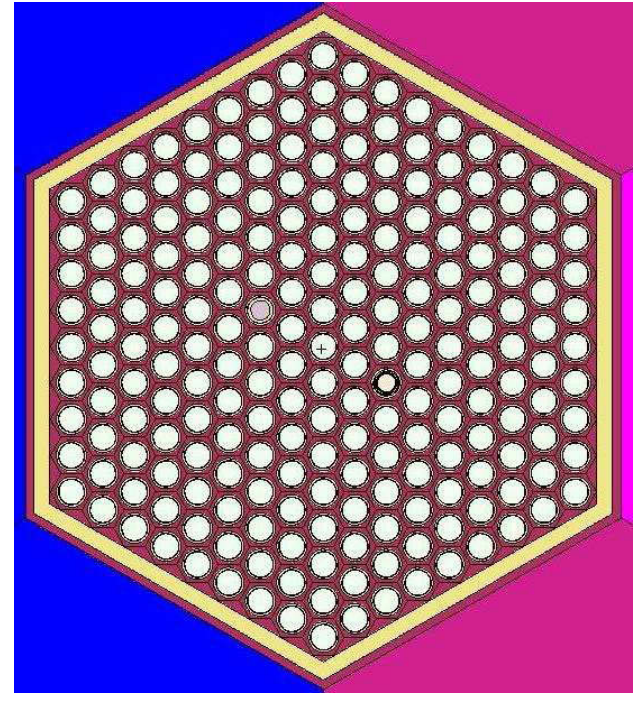

(b) Subassembly containing irradiated samples

Figure 15: Radial cross sectional view of the PROFIL-2 model by MCNP5.

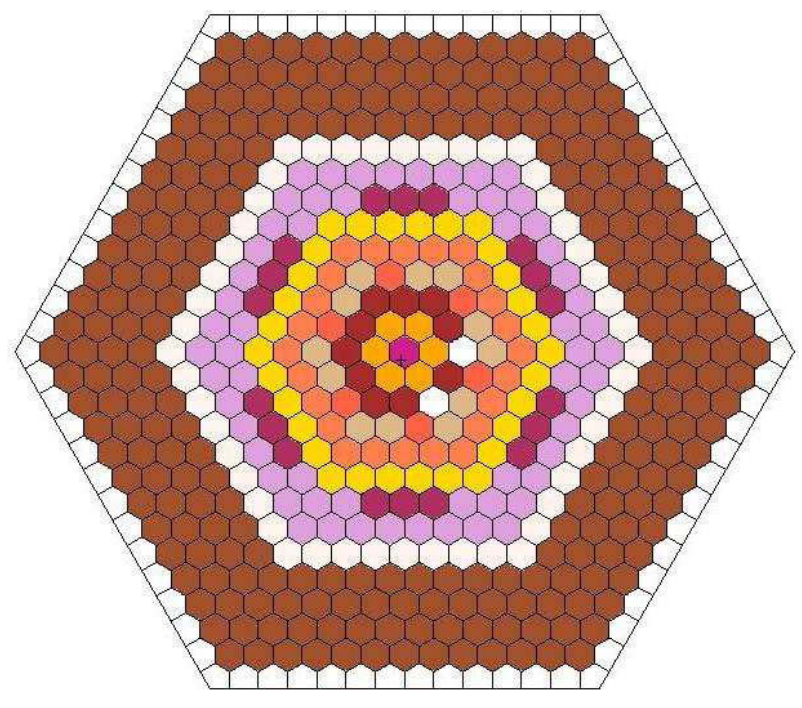

(a) Radial configuration during TRAPU experiment

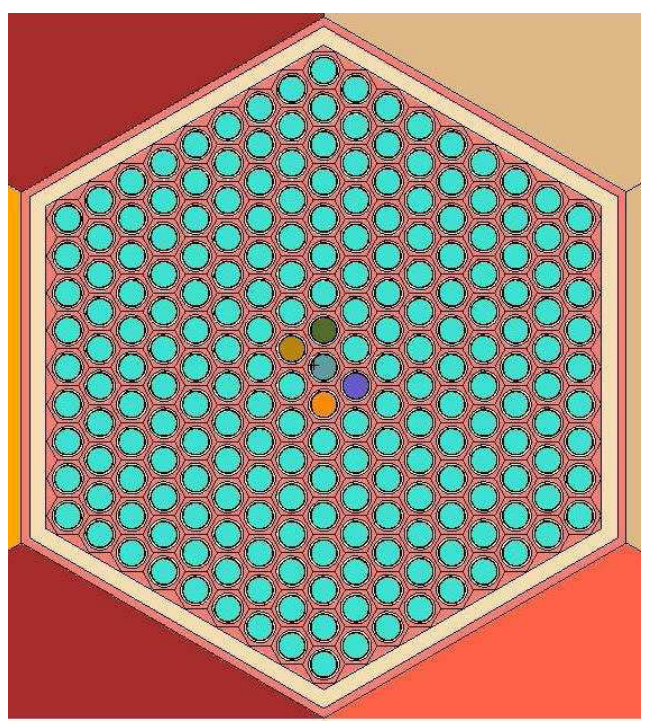

(b) Subassembly containing irradiated samples

Figure 16: Radial cross sectional view of the TRAPU model by MCNP5. 


\section{CONCLUSIONS}

This report has presented the status of activities performed at INL under the AFCI Work Package on "Uncertainty Reduction Analyses" that has a main goal the reduction of uncertainties associated with nuclear data on neutronic integral parameters of interest for the design of advanced fast reactors under consideration by the FCR\&D program.

First an analysis of uncertainty evaluation has been presented using the new covariance data (AFCI version 1.2) made available by BNL. The results of the study indicate that a careful analysis is still needed in order to define the most appropriate and effective strategy for data uncertainty reduction. It seems that, besides a further consolidation of the present covariance data libraries, a strategy of combined use of integral and differential measurements should be further pursued in order to meet future requirements.

Subsequent analyses of a number of experiments, among those selected in the previous fiscal year and available, are presented making use of ENDF/B-VII data. These experiments include: updating of the ZPR-6/7 assembly (improved model and spectral indices), ZPPR-9 assembly (only simplified model available), ZPPR-10 (full detailed model), and irradiation experiments including PROFIL-1 detailed analysis and modeling of the PROFIL-2 and TRAPU experiments.

The analysis of the ZPR and ZPPR configurations have indicated a good performance of the ENDF/B cross section data for the core criticality, most of the spectral indices and some reactivity coefficients.

The analysis of the irradiation experiment PROFIL-1 has shown large discrepancies of ENDF/B-VII data for capture cross sections of Pu isotopes (Pu238, Pu239, and Pu242) and Am243. The (n,2n) cross sections of Pu239 and Pu240 appear to be largely underestimated. Regarding fission products, the capture cross sections of Ru101, Pd105, Cs133, and Sm149 need to be improved.

Because the detailed information of some experiments (in particular ZPPR-9 and ZPPR-15) were not available as well the more reliable covariance data (AFCI version 2.0) it was decided to postpone the planned adjustment. These data should be available next fiscal year. Therefore, for yhe next fiscal year the work to be performed at INL under the support of this Work Package will focus on two main activities:

- Complete analysis for the remaining list of experiments (including ZPPR-9 and ZPPR-15 when available) and finalize irradiation experiment analysis, that at this moment have been only partially analyzed" with ENDF/B-VII data (In particular PROFIL-2 and TRAPU)

- Perform a full multigroup adjustment in the energy structure (33 groups) that has been agreed for design calculations.

For this latter task, the improved covariance matrix AFCI 2.0 is expected to be used. 


\section{REFERENCES}

[1] "OECD/NEA WPEC Subgroup 26 Final Report: Uncertainty and Target Accuracy Assessment for Innovative Systems Using Recent Covariance Data Evaluations", 2008

[2] G. Rimpault et al., "The ERANOS Code and Data System for Fast Reactor Neutronics Analyses", Proc. PHYSOR 2002 Conference, Seoul (Korea), October 2002.

[3] D. Rochman, M. Herman, P. Oblozinsky and. S. F. Mughabghab, "Preliminary Cross-Section Covariances for WPEC Subgroup 26,” Tech. Rep. BNL-77407-2007-IR, Brookhaven National Laboratory, 2007

[4] P.Oblozinsky, C.M. Mattoon, M. Herman, S.F. Mughabghab, M.T. Pigni National Nuclear Data Center, (BNL), P. Talou, G.M. Hale, A.C. Kahler, T. Kawano, R.C. Little, P.G. Young, LANL, Los Alamos, "Progress on Nuclear Data Covariances: AFCI-1.2 Covariance Library" September $28,2009$.

[5] G. Palmiotti, M. Salvatores, G. Aliberti, H. Hiruta, R. McKnight, P. Oblozinsky, and W.S. Yang, "A global approach to the physics validation of simulation codes for future nuclear systems", Annals of Nuclear Energy 36 (2009) 355-361.

[6] X-5 Monte Carlo Team, "MCNP - A General Monte Carlo N-Particle Transport Code, Version 5," LA-UR-03-1987, Los Alamos National Laboratory (2003).

[7] International Handbook of Evaluated Reactor Physics Benchmark Experiments, NEA/NSC/DOC(2006)1, OECD-NEA, March (2008)

[8] International Handbook of Evaluated Criticality Safety Benchmark Experiments, NEA/NSC/DOC(95)03, September 2008 Edition.

[9] G. Palmiotti, M. Salvatores, and R. N. Hill, "Sensitivity, Uncertainty Assessment, and Target Accuracies Related to Radiotoxicity Evaluation”, Nucl. Sci. Eng. 117, 239 (1994)

[10] J. Tommasi, E. Dupont, and P. Marimbeau, "Analysis of Sample Irradiation Experiments in Phenix for JEFF-3.0 Nuclear Data Validation,” Nucl. Sci. Eng., 154, 119-133 (2006).

[11] M. Carnoy, "Donnees necessaries au calcul neutronique du Coeur de Phenix au cours du 1st cycle de fonctionnement", 2NT DRNR/SEDC/SPNR, 77-143. 